This is the peer reviewed version of the following article: Klippstein, Helge, Sanchez, Alejandro Diaz De Cerio, Hassanin, Hany, Zweiri, Yahya and Seneviratne, Lakmal (2018) Fused deposition modelling for unmanned aerial vehicles : a review. Advanced Engineering Materials, 20(2), 700552. ISSN (print) 1438-1656, which has been published in final form at http://dx.doi.org/10.1002/adem.201700552. This article may be used for non-commercial purposes in accordance with Wiley Terms and Conditions for Self-Archiving. 


\title{
Fused Deposition Modelling for Unmanned Aerial Vehicles (UAVs): A Review
}

Helge Klippstein ${ }^{1}$, Alejandro Diaz De Cerio Sanchez ${ }^{1}$, Hany Hassanin ${ }^{1, *}$, Yahya Zweiri ${ }^{1,2}$ and Lakmal Seneviratne ${ }^{3}$

${ }^{1}$ School of Mechanical and Aerospace Engineering, Kingston University, London SW15 3DW, UK

${ }^{2}$ Visiting Associate Professor, Robotics Institute, Khalifa University of Science and Technology, P.O. Box 127788, Abu Dhabi, United Arab Emirates

${ }^{3}$ Robotics Institute, Khalifa University of Science and Technology, P.O. Box 127788, Abu Dhabi, United Arab Emirates

Keywords: unmanned aerial vehicles (UAVs), additive manufacturing, fused deposition modelling

[*] Corresponding author: Dr Hany Hassanin, Email:h.hassanin@ kingston.ac.uk

\begin{abstract}
Additive Manufacturing (AM) is a game changing production technology for aerospace applications. Fused deposition modelling is one of the most widely used AM technologies and recently has gained much attention in the advancement of many products. This paper introduces an extensive review of fused deposition modelling and its application in the development of high performance unmanned aerial vehicles. The process methodology, materials, post processing, and properties of its products are discussed in details. Successful examples of using this technology for making functional, lightweight and high endurance unmanned aerial vehicles are also highlighted. In addition, major opportunities, limitations, and outlook of fused deposition modelling are also explored. The paper shows that the emerge of fused deposition modelling as a robust technique for unmanned aerial vehicles represents a good opportunity to produce compact, strong, lightweight structures, and functional parts with embedded electronic.
\end{abstract}




\section{Introduction}

Unmanned aerial vehicles (UAVs) have significantly developed since they first appeared during World War I. However, the research and development of UAVs in recent years have gained much attention, not only for military purposes, but also for civil applications. UAVs are defined as generic air vehicles capable to work autonomously without a pilot on-board ${ }^{[1]}$. They are considered as a valuable and ubiquitous technology in many applications such as mapping, topography, telecommunications, surveillance, and agricultural management ${ }^{[2-7]}$. The advancement of this technology into such applications was possible for various reasons, such as innovations in structural and aerodynamic designs, introduction of new lightweight materials and manufacturing technologies, and development of sensing and control systems. Designs of UAVs have been evolved into several categories in order to provide the optimal solution in terms of functionality and cost. The main differences between these categories are the lift and thrust generation systems ${ }^{[8]}$. The most common types of UAVs are multi-rotors, fixed-wing, flapping wing and hybrid systems. A schematic diagram of UAVs' categories is shown in Error! Reference source not found.

Multi-rotor system is the most popular type of UAVs because it is used for versatile applications, such as cargo delivery, aerial photography, recreational purposes, and sports activities. The number of rotors can goes from one and up to twelve. However, the most common models are the quadcopter and the hexacopter. The structure of this system is generally a fixed frame with an equal distribution of the rotors with respect to the aircraft's centre of mass ${ }^{[5,6,9]}$. Fixed-wing UAVs system, on the other hand, presents the closest resemblance to the classic avionics models. It is defined as "an air-vehicle" that uses fixed wings in combination with forward thrust to generate lift ${ }^{[8]}$. Generally, fixed-wing UAV is used in accurate mapping and monitoring applications due to its long flight endurance and high altitude operability, which allows covering long distances, and carrying electronic 
equipment such as cameras and sensors ${ }^{[10,11]}$. Flapping wing UAVs, also known as Ornithopter, mimic the mechanics of flying birds and insects to generate lift by using semi rigid articulated wings. In most cases, the wings consist of an ultralight frame covered with a membrane or rigid surface to generate lift. Flapping wing UAVs are mainly used for research purposes thanks to their reduced size and improved manoeuvrability, along with their high flight efficiency when compared to both the multirotor and fixed wing systems. In addition, their low noise output makes them ideal for natural and environmental research such as animal tracking and recording ${ }^{[12,13]}$. Finally, hybrid UAVs system is a combination of the multi-rotor and fixed-wing UAVs. The combination of these two models has enhanced its capabilities to allow a vertical take-off and landing ${ }^{[14]}$.

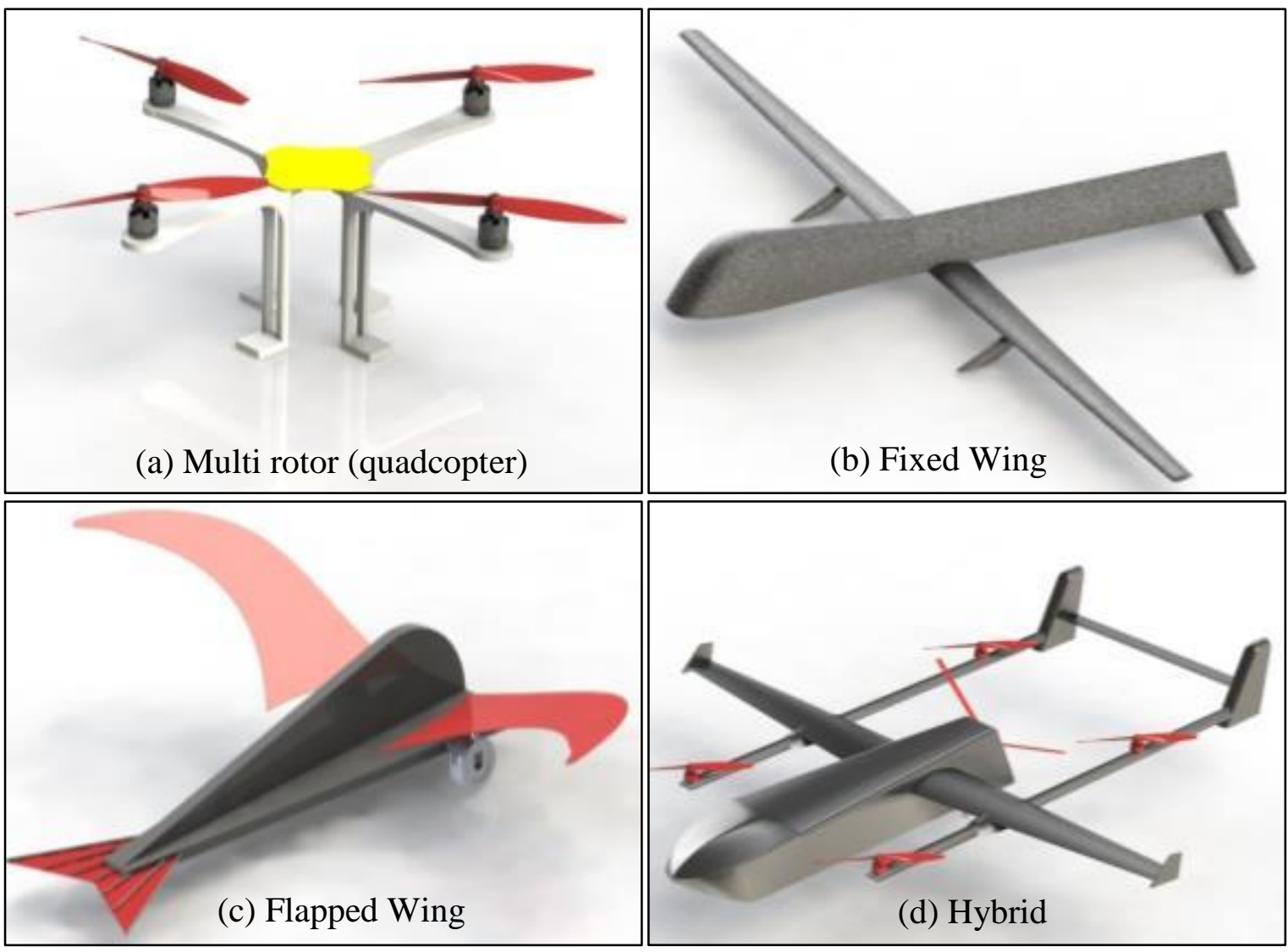

Figure 1: Different UAVs Configurations. 
Successful developments of UAVs depend on producing low-cost and high endurance platforms. Reducing the structural weight is one of the influential factors to improve UAVs' performance and increase their payload carrying capacity. This can be achieved by using lightweight structure and electronics. However, there are limitations in reducing UAVs weight, especially with regards to the battery pack and equipped electronics. Hence, UAVs' frame becomes the relevant part in the design process.

Materials developments and advances in manufacturing technologies are useful tools to improve lightweight frames. One of the revolutionary manufacturing technologies is additive manufacturing (AM). Owing to its high design freedom, lighter parts with high functionality started to contribute in the advancement of a variety of industries such as aerospace ${ }^{[15,16]}$, automotive ${ }^{[17-19]}$, biomedical ${ }^{[20-22]}$, fashion and art ${ }^{[23]}$. Additive manufacturing, Rapid prototyping, and 3D printing are often taken as synonym. However, there are differences between those terms. Rapid prototyping is the concept of fast generated prototypes based on a digital model. This can be done via material removal as well as additive manufacturing methods ${ }^{[24]}$. The definition of additive manufacturing is purely the class of material adding technologies ${ }^{[25-27]}$. On the other hand, the term "3D printing" is basically the method within the AM class of ink-jet or ploy-Jet technologies ${ }^{[28]}$. AM technique was invented in 1984 and the first prototyping machine was built by Chuck Hull ${ }^{[29]}$ based on the stereo-lithography method. However, the technology has gained much attention during the past ten years due to significant improvements in product lifecycle management (PLM) solutions and in computer numerical control (CNC) techniques. AM is not only considered as a disruptive technology ${ }^{[30]}$, but also as one of the fast growing sectors in the market. Based on Wohlers Associates report ${ }^{[31]}$, the estimated global market for AM is more than US\$ 5.1 billion in 2015 with a corporate annual growth rate (CAGR) of more than $25.9 \%$. A strong market growth is furthermore expected, as the technology becomes more mature for end users with 
expectations to worth about $\$ 21$ billion by $2020^{[31]}$. This is also supported by investigating the number of research publications in the past 26 years. In

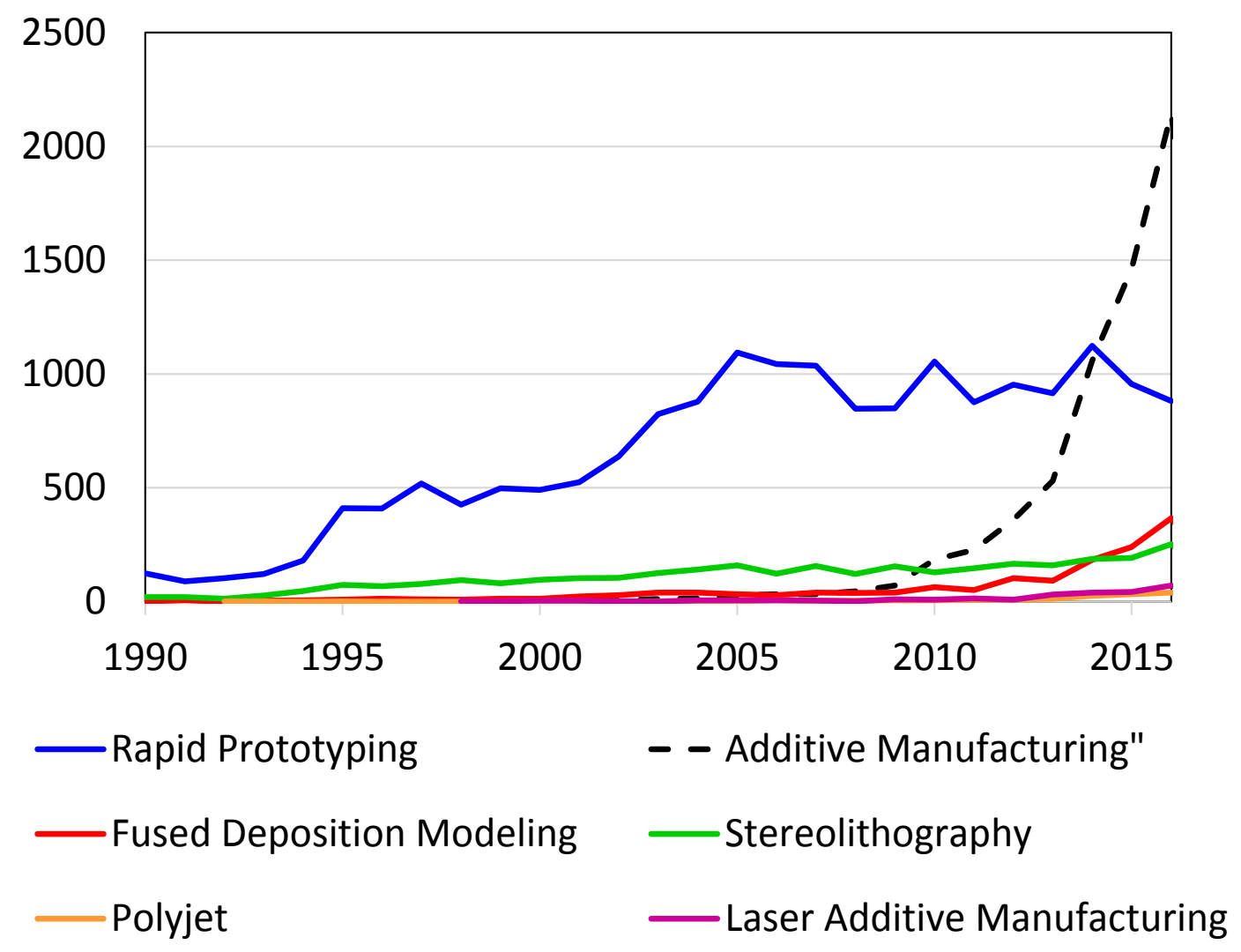

Figure 1, the Scopus search results per year are presented. It can be noted that the additive manufacturing term is becoming more important, as it opens, the verbal term for end user products while the rapid prototyping term is declining in number per years, though, there is still high interest on prototyping research. 


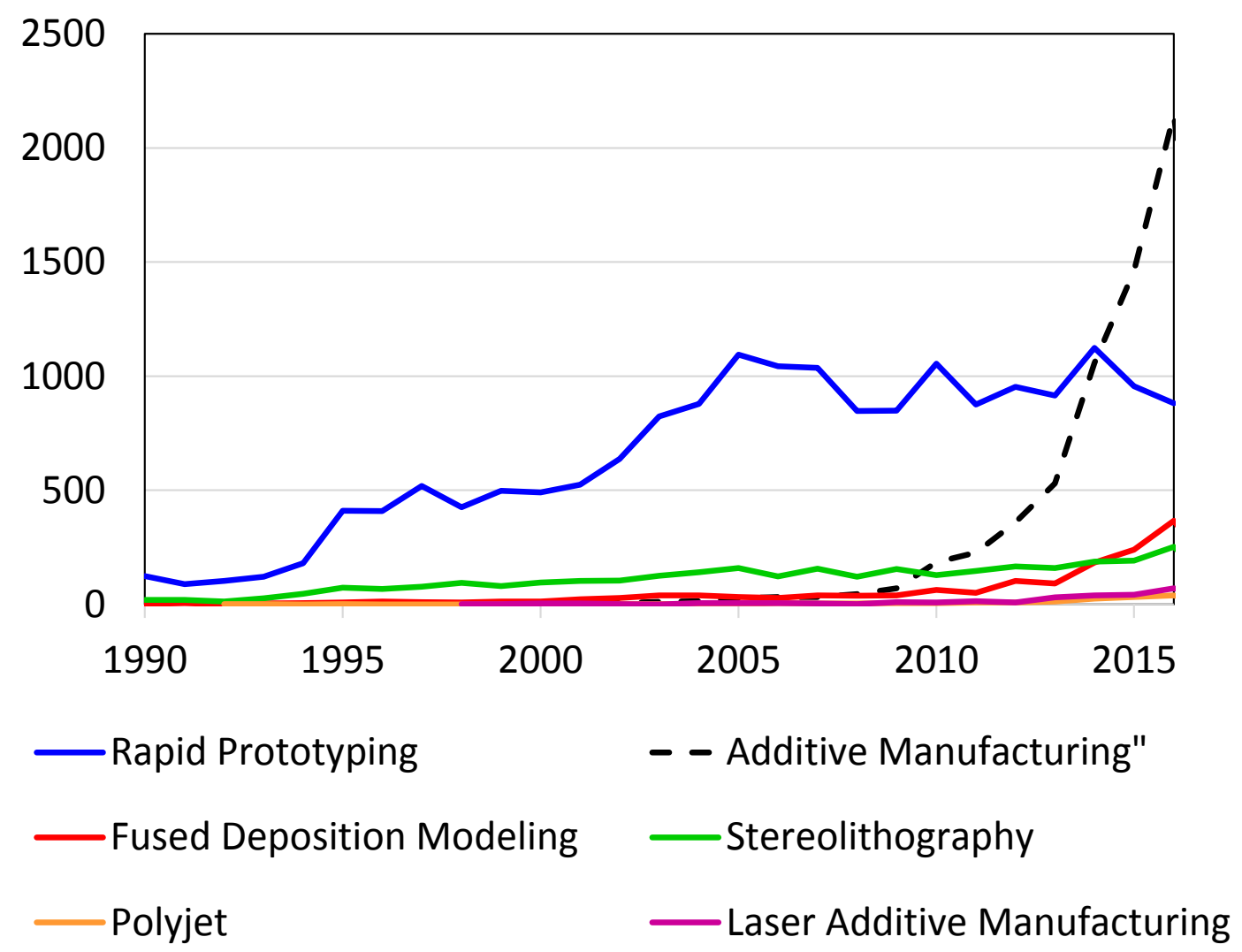

Figure 1: Number of AM publications globally per year.

The manufacturing process of AM products starts with creating a digital CAD model represents the physical part. Then, the CAD model is sliced into layers and fed to the AM machine. The machine builds the part layer by layer until the physical part is achieved. Whilst there are different AM technologies available in the market, the international organization for standardization and American society for testing and materials (ISO/ASTM) created the main set of standards of AM ISO/ASTM 52900:2015 and grouped them into seven main categories as listed in Table 1.

Table 1: Summary of AM technologies

\begin{tabular}{l|l|l|l|l}
\hline Technology & Materials & Techniques & $\begin{array}{c}\text { Consolidation } \\
\text { tool }\end{array}$ & References \\
\hline
\end{tabular}




\begin{tabular}{l|c|c|c|c}
\hline Binder Jetting & $\begin{array}{c}\text { Polymer, Metal, } \\
\text { Ceramics }\end{array}$ & Poly-Jet, Multi-Jet, Ink-Jet & $\begin{array}{c}\text { Binder/ Photo- } \\
\text { polymerization }\end{array}$ & {$[32,33]$} \\
\hline $\begin{array}{l}\text { Direct Energy } \\
\text { Deposition }\end{array}$ & Metal, Composites & $\begin{array}{c}\text { Laser Energy Net Shaping (LENS), } \\
\text { Laser Cladding (LC), Laser } \\
\text { Deposition Welding (LDW) }\end{array}$ & Laser & {$[34]$} \\
\hline $\begin{array}{l}\text { Material } \\
\text { Extrusion }\end{array}$ & $\begin{array}{c}\text { Polymer, Metal, } \\
\text { Ceramics, Composite }\end{array}$ & Fused Deposition Modelling (FDM) & Thermal & {$[36]$} \\
\hline $\begin{array}{l}\text { Powder Bed } \\
\text { Fusion }\end{array}$ & $\begin{array}{c}\text { Polymer, Metal, } \\
\text { Composite }\end{array}$ & $\begin{array}{c}\text { Selected Laser Sintering/Melting } \\
\text { (SLS/SLM), Direct Metal Laser } \\
\text { Sintering (DMLS), Electron Beam } \\
\text { Melting (EBM) }\end{array}$ & $\begin{array}{c}\text { Laser, Electron } \\
\text { Beam }\end{array}$ & {$[35]$} \\
\hline $\begin{array}{l}\text { Sheet } \\
\text { Lamination }\end{array}$ & Metal, Composite & $\begin{array}{c}\text { Laminated Object Manufacturing } \\
\text { (LOM), Ultrasonic Additive } \\
\text { Manufacturing (UAM), Solid Foil } \\
\text { Polymerization (SFP) }\end{array}$ & $\begin{array}{c}\text { Cutting and } \\
\text { Gluing }\end{array}$ & {$[45]$} \\
\hline $\begin{array}{l}\text { Stereo lithography (SLA), } \\
\text { Continuous Liquid Interface } \\
\text { polymerization }\end{array}$ & Polymer, Ceramics & Light & {$[139,140]$} \\
\hline
\end{tabular}

Material or binder jetting technology is based on selectively deposit droplets. The material is supplied through nozzles and often cured via photo-polymerization. The print head is similar to the conventional paper printers, and while, in classic ink jet printers, it is possible to print different colours, material jetting technology is also capable to print different materials ${ }^{[32,33]}$. In direct energy deposition (DED), the build material is supplied through a nozzle and 
shielded with the aid of an inert gas ${ }^{[34]}$. The material is melted in a laser focal point and deposited to create dense $3 \mathrm{D}$ structures or to coat a surface and/or specific feature of a part droplet by droplet ${ }^{[35]}$. In material extrusion (ME), a nozzle extrudes molten materials to generate the AM part. The raw material is in form of filaments or paste ${ }^{[36]}$. Hence, a wide range of thermoplastic polymers and ceramics can be used ${ }^{[37]}$. Fuse deposition modelling (FDM) is the most used material extrusion technique where the material is extruded, heated, and deposited line by line. It is a popular technique used on many industrial and domestic applications ${ }^{[38]}$. In powder bed fusion, a layer of powder is spread onto a building substrate while an electron or a laser beam is used to selectively consolidate a layer of metal powder. Next, a second powder layer is spread, and the process is repeated until the required geometry is achieved ${ }^{[35]}$. Powder bed fusion systems include the following commonly used techniques: selective laser melting (SLM) and electron beam melting (EBM). Selective laser melting (SLM) is one of the important techniques to build near net shape metal components with complex geometries. This system uses a laser beam as an energy source to build metal components by selectively melting layers of metal powder according to the CAD design ${ }^{[20 \text {, }}$ ${ }^{39]}$. SLM technology offers numerous merits over the other AM techniques, besides it can build complex shaped components with a high degree of accuracy and resolution ${ }^{[40-42]}$. Compared to SLM, EBM substitutes the laser beam with an electron beam as energy source. In EBM, an electron beam can reach a velocity of up to $8000 \mathrm{~m} / \mathrm{s}$ while the laser beam in SLM can achieve up to $10 \mathrm{~m} / \mathrm{s}$. In addition, vacuum conditions and a preheated substrate are required for EBM. As such, dense components can be achieved using EBM but the process is restricted to conductive materials only ${ }^{[43,44]}$. Sheet lamination (SL) is a combination of material subtraction and adding methods. A sheet of material is cut and laminated to generate a 3D model ${ }^{[45]}$. Finally, vat photo-polymerization is a well-known AM technique to produce 3D structures from curable resin materials subjected to photo-polymerization. Stereo- 
lithography apparatus (SLA) and continuous liquid interface production (CLIP) are two vat photo-polymerization techniques used to print high quality polymer and ceramic components [32].

$\mathrm{AM}$ techniques can process a wide range of materials as shown in Table 1, their numbers continue to expand as improved technologies, and optimized processes are introduced to suit materials associated with difficult processability. Among AM techniques, fused deposition modelling (FDM), is considered one of the most widely used AM technologies. This technique is also a cost effective tool for various applications since it can manufacture robust parts quickly and reliably ${ }^{[46]}$. Furthermore, by comparing the number of publications of the most widely used AM techniques, specifically, FDM, poly-jet, stereo-lithography, and laser based AM, it can be clearly see that research publications of FDM is the most growing technology

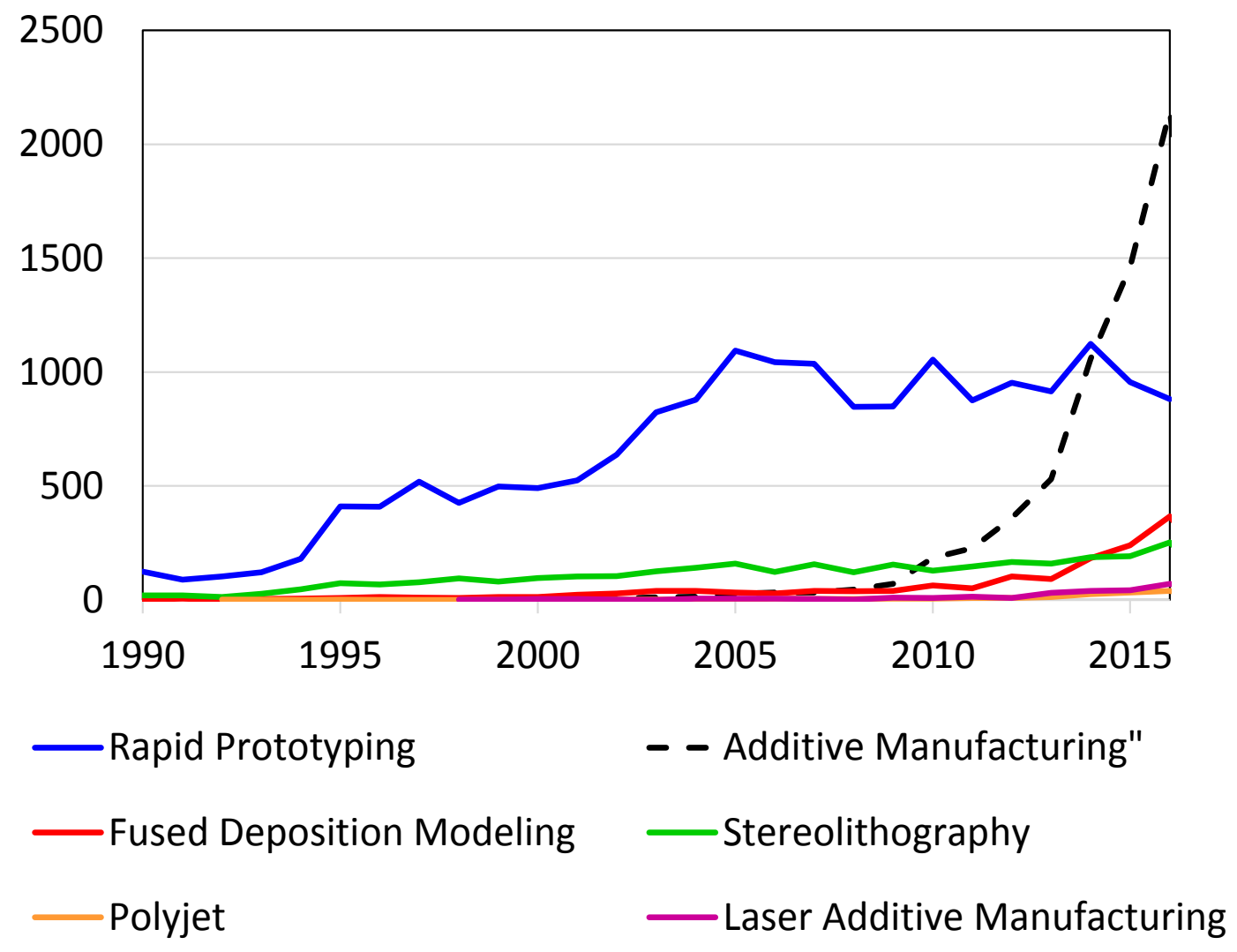

Figure 1. 
To the best of the authors' knowledge, few review papers have been reported on FDM and they were focused on pharmaceutics, drug delivery, composites, and investment casting ${ }^{[38,47-}$ ${ }^{49]}$. No review reports were found on the application of FDM in aerospace, robotics or UAVs industries. This paper provides an overview of fused deposition modelling and its role in the advancement of unmanned aerial vehicles. The motivation is to present the state of the art in manufacturing of unmanned aerial vehicles using fused modelling deposition as one of the robust additive manufacturing techniques. The concept of fused deposition modelling technology, the properties of FDM products and materials are explained and discussed. The review also highlights the potential and limitations of using FDM in the development of UAVs.

\section{Fused Deposition Modelling}

\subsection{Process Overview}

Fused deposition modelling is one of the material extrusion AM techniques and can be considered as one of the rapidly growing process. Light or laser based technologies can typically be used to print parts with good resolution and high speed ${ }^{[50]}$. However, the availability of FDM technology along with its low cost made it an important printing 
technology in the market. A schematic of the process is shown in

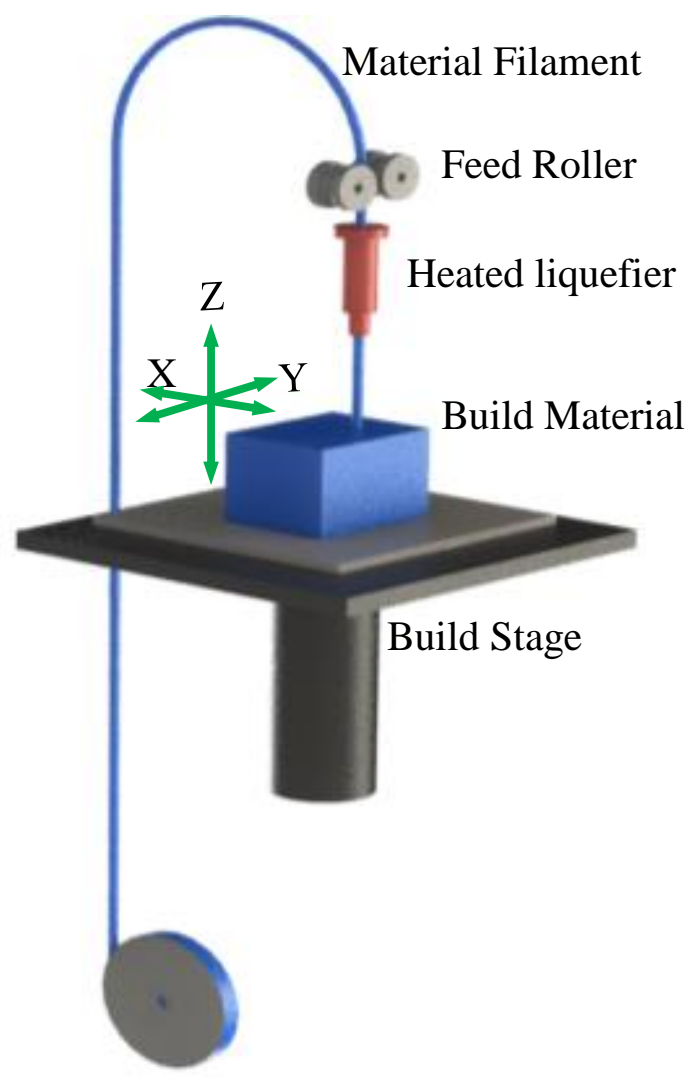

Figure 2. As shown in the figure, the process combines three functions. First, the material is fed with the aid of rotating rollers. Second, the thermoplastic raw material is melted using an electric heating unit. Third, the soften material is extruded through a nozzle and deposited to build complex parts layer by layer. Typically, a heated bed and a closed chamber are used in most FDM printers to allow a slow cooling of the deposited material, which prevents warping of the printed sample. FDM machines are commercially available in different versions. The simplest version uses one material to build both the part and the support structure. A different type has two extrusion heads, i.e one is used to build the part and the other is used to build the support structure. Other versions use multiple heads to build structures with different colures. There are several attempts were introduced to improve FDM process. An advanced approach was used to mix different materials in the extrusion head before deposition ${ }^{[51]}$. This allows 
controlling materials content and properties of the FDM part. Furthermore, Du et al. ${ }^{[52]}$ modified FDM printer with two-laser heating unites, targeting the filament material. With this improvement, they were able to build large thin walled parts, decreasing surface roughness and improved the mechanical properties. Lee et al. ${ }^{[53]}$ used a five-axis hybrid milling- FDM machine. Thus, it was possible to reduce the amount of support structure and to improve surface finish.

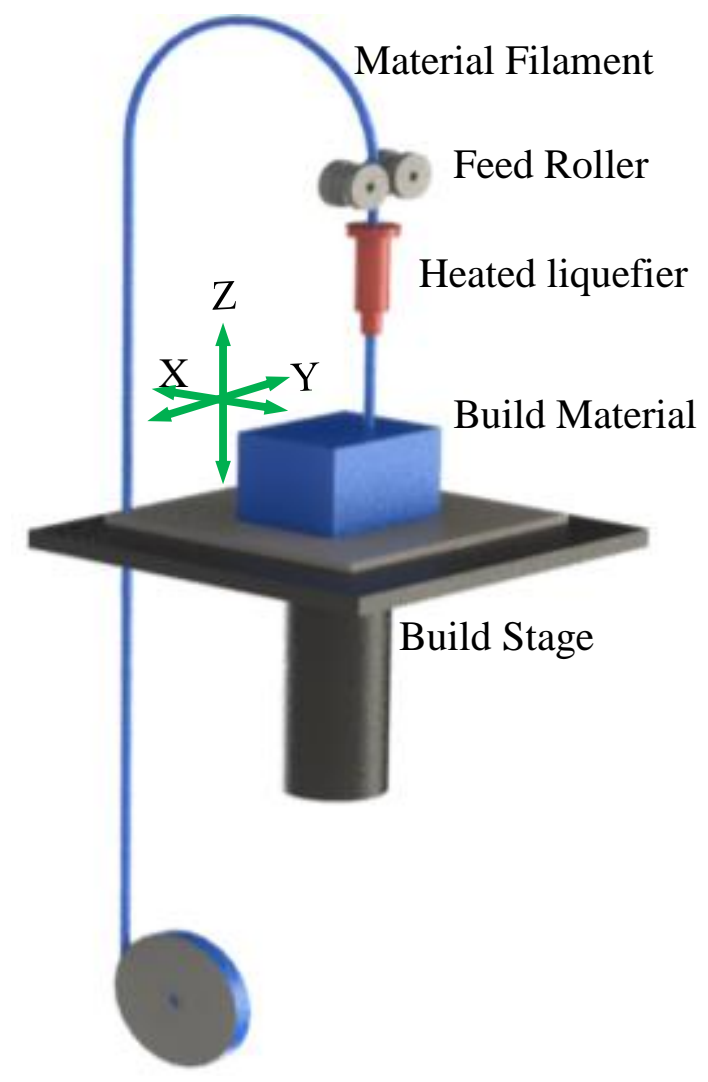

Figure 2: A schematic of FDM process.

\subsection{FDM Materials and properties}

Currently, there is a wide range of materials available for FDM. Thermoplastic polymers are well established materials for FDM. On the other hand, the demand on composites, ceramics, 
and metals are growing to improve FDM parts functionalities. Details of FDM materials and their properties are explained in the following section. 


\subsubsection{Thermoplastic Polymers}

Thermoplastic polymers are widely used in FDM processes because it is easy to shape them into filaments with specific sizes. In addition, their melting temperatures are relatively low and their viscosities are suitable during extrusion and deposition. The most common materials used in FDM and their properties are presented in Table 2. Acrylonitrile-Butadiene-Styrene (ABS) and Poly Lactic Acid (PLA) are two popular materials for FDM. ABS is the popular material used to manufacture Lego bricks. It is durable, easy to process, and cheap. Disadvantages of ABS include its moderate strength, moderate flexibility, and the need for a heated bed to process it ${ }^{[54-56]}$. In addition, fumes are typically arisen during ABS printing. On the other hand, PLA is a biodegradable material and therefore more environmentally friendly than other polymers. It is stronger and more rigid than ABS. However, since PLA is biodegradable material, it is prone to moisture absorption in a short time. In addition, PLA has a low impact strength, low glass transition temperature of $60-65{ }^{\circ} \mathrm{C}$ and hence has a low service temperature ${ }^{[56-58]}$. High Impact Polystyrene (HIPS) is also a biodegradable thermoplastic material and mainly used as a support material for ABS. It is also used for packaging and food industry. HIPS is difficult to process using FDM as it tends to distort and adhere to the bed ${ }^{[54,56]}$. Nylon belongs to the polyamides thermoplastic polymers. It is a light, strong, and flexible material. It has a Young's modulus of 1138-1282 MPa, which makes it the most flexible FDM material. It can be used for a wide range of applications such as containers, functional parts, tools, and toys. However, it is also sensitive to moisture and can absorb humidity from air in a short time ${ }^{[54,56,59]}$. Acrylonitrile styrene acrylate (ASA) is developed as an alternative to ABS. Its physical and mechanical properties are similar to ABS. Its outstanding weather and chemical resistance make it suitable for outdoor applications ${ }^{[54,56]}$. Copolyester (PETG) is a co-polyester thermoplastic FDM material with reasonable tensile strength, impact strength, durability, and flexibility. The material is easy to 
process without the need to a heated bed and it does not produce fume during building ${ }^{[56,60]}$. Polycarbonate (PC) is one of the thermoplastics that contain carbonate in its chemical structure. It is one of the strongest and toughest FDM filaments. It has a glass transition temperature of $147^{\circ} \mathrm{C}$, which makes it ideal for high temperature plastic applications ${ }^{[54,56,59]}$. Polyetherimide (PEI) is an amorphous and a semi-transparent thermoplastic. It is one of the high-performance thermoplastic materials available for FDM. Polyetherimide (PEI) satisfies the flame, smoke and toxicity standards and therefore is used for wide range of aerospace applications ${ }^{[54]}$. Ultem is a family of polyetherimide polymers which was developed by SABIC. It is a heat, flame, and solvent resistance material. It is also has a high mechanical properties at elevated temperature of up to $170{ }^{\circ} \mathrm{C}{ }^{[61]}$. Polyphenylsulfone (PPSF) is a high performance and heat resistant polymer. It has excellent chemical and thermal properties which makes it suited aerospace, automotive, and electronics applications ${ }^{[62]}$.

In general, thermoplastic polymers are popular for FDM. However, properties such as low strength, low service temperature, high insulation, low wear and friction prevent the use of FDM when high thermal and electrical conductivity, high service temperature, lightweight and multifunctional applications are required. 
Table 2: Typical FDM polymer materials.

\begin{tabular}{c|c|c|c|c|c}
\hline Material & $\begin{array}{c}\text { Density } \\
(\mathbf{g} / \mathbf{c c})\end{array}$ & $\begin{array}{c}\text { Young's } \\
\text { modulus } \\
\mathbf{( M P a})\end{array}$ & $\begin{array}{c}\text { Tensile } \\
\text { Strength } \\
(\mathbf{M P a})\end{array}$ & $\begin{array}{c}\text { Processing } \\
\text { Temperature } \\
(\mathbf{C})\end{array}$ & References \\
\hline $\begin{array}{c}\text { Acrylonitrile-Butadiene- } \\
\text { Styrene (ABS) }\end{array}$ & 1.05 & $2180-2230$ & $26-31$ & $250-280$ & {$[54,55,60]$} \\
\hline Poly(lactic acid) PLA & 1.27 & 3368 & 56.6 & $190-220$ & {$[57,58,60]$} \\
\hline Nylon 12 & 1.05 & $1138-1282$ & $28-32$ & $255-275$ & {$[54,59]$} \\
\hline $\begin{array}{c}\text { Acrylonitrile Styrene } \\
\text { Acrylate (ASA) }\end{array}$ & 1.06 & $1950-2010$ & $27-29$ & $240-260$ & {$[54]$} \\
\hline $\begin{array}{c}\text { High Impact } \\
\text { Polystyrene (HIPS) }\end{array}$ & 1.05 & 1650 & 16 & $210-230$ & {$[54,56]$} \\
\hline Copolyester (PETG) & 1.27 & 2100 & 50 & $220-245$ & {$[56,60]$} \\
\hline Polycarbonate (PC) & 1.24 & $1958-1944$ & $30-40$ & $230-255$ & {$[54,56,59]$} \\
\hline Polyetheriminde (PEI) & 1.27 & $2150-2770$ & 69.81 & $330-350$ & {$[54]$} \\
\hline ULTEM & 1.27 & $2200-3580$ & $44-110$ & $375-420$ & {$[61]$} \\
\hline Polyphenylsulfone & 1.29 & 2068 & 55 & $360-390$ & {$[62]$} \\
\hline (PPSF) & & &
\end{tabular}

\subsubsection{Composite and Nano-composite Materials}

FDM composites consist of two or more different materials that are shaped into filaments and printed using FDM. At least one of the FDM composite materials is a thermoplastic polymer. They are developed to obtain specific properties that are not available with the pure thermoplastic polymer such as high thermal or electrical conductivity. Recently, several researchers have carried out studies to develop new composites adequate for FDM. Filament made from metal-polymer composite was developed by dispersing metal fine powder into a polymer matrix. Garge et al. developed Fe-nylon 6 filament for ABS 3D printer. They used different Fe/ nylon 6 ratios and investigated the wear and friction properties of the FDM parts. They concluded that the Fe-nylon 6 composite filaments showed uniform Fe dispersion in the 
Nylon matrix. In addition, the developed composite samples showed a lower friction coefficient and a better wear resistance than the recommended ABS material ${ }^{[63]}$. Another study focused on developing copper-ABS filaments and determined its effect on the surface characteristics of the parts. It was found that, an improvement of the contact angle was achieved by introducing copper powder into ABS matrix ${ }^{[64]}$. A mixture of copper and iron particles was also introduced by Hwang et al. ${ }^{[65]}$ to investigate the thermo-mechanical properties of the new composite. The printed material was characterised and it was found that the mechanical strength of the samples was decreased with the addition of metal powder. However, the thermal conductivity was improved which makes it ideal for printed circuits and electromagnetic devices. Furthermore, Boparai et al, used $\mathrm{Al}-\mathrm{Al}_{2} \mathrm{O}_{3}$ particles to reinforce Nylon 6 matrix and produced metal/composite filaments. The developed composite filaments showed poor mechanical characteristics when compared to commercial ABS material. However, the thermal stability and the wear resistance were also improved ${ }^{[66,67]}$.

Ceramic particles have been also used and dispersed into polymers to produce filament with good bio-biocompatibility and high corrosion resistance. Tricalcium phosphate (TCP) ceramic was dispersed into polypropylene (PP) matrix to fabricate polymer-ceramic composites for biocompatible bone graft applications. PP-TCP non-toxic composite scaffolds with controlled porosity were successfully manufactured using FDM process. It was found that scaffold with $160 \mu \mathrm{m}$ pore size and porosity of $36 \mathrm{vol} . \%$ revealed the highest compression strength ${ }^{[68]}$. In another study, TCP was used with PLA to produce biodegradable thermoplastic implants. The study showed that the crystallinity of the samples and hence the degradation behaviour is highly affected by the processing conditions ${ }^{[69]}$. In recent years, fibre and nanocomposites materials have been investigated to produce lightweight and multifunctional parts using FDM. ABS and PLA reinforced with carbon fibre and Carbon nanotubes (CNT) were introduced 
aiming to improve the microstructural and mechanical properties of the samples ${ }^{[70]}$.
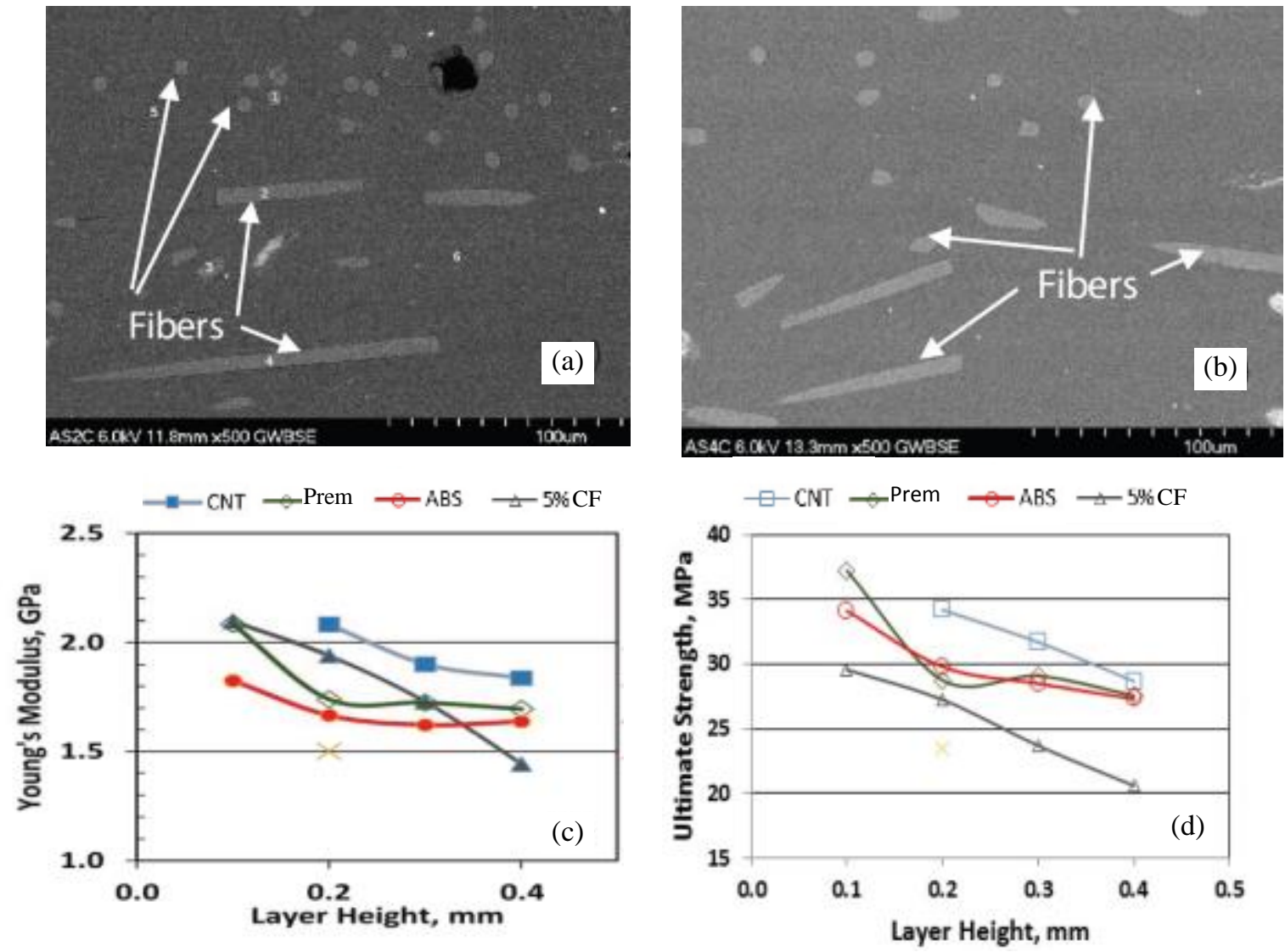

Figure 3 (a, b) shows SEM images of the fibre composite samples in 0.2 and $0.4 \mathrm{~mm}$ layer thickness. As shown, the carbon fibre can be clearly visible within the PLA matrix. The mechanical characterisation of the samples showed that there was a significant improvement in the elastic modulus and the ultimate strength of the CNT samples when compared to pure ABS or the carbon fibre composite samples. CNT and carbon fibre materials are stronger and stiffer than ABS and PLA matrix. In addition, the ABS and PLA matrix transfers part of the applied load to the reinforcing fibres. Hence, the movement of the reinforced prints is restricted so that the strength and the stiffness improve. The degree of such improvement 
depends on the bonding between the matrix and the reinforced fibre, see
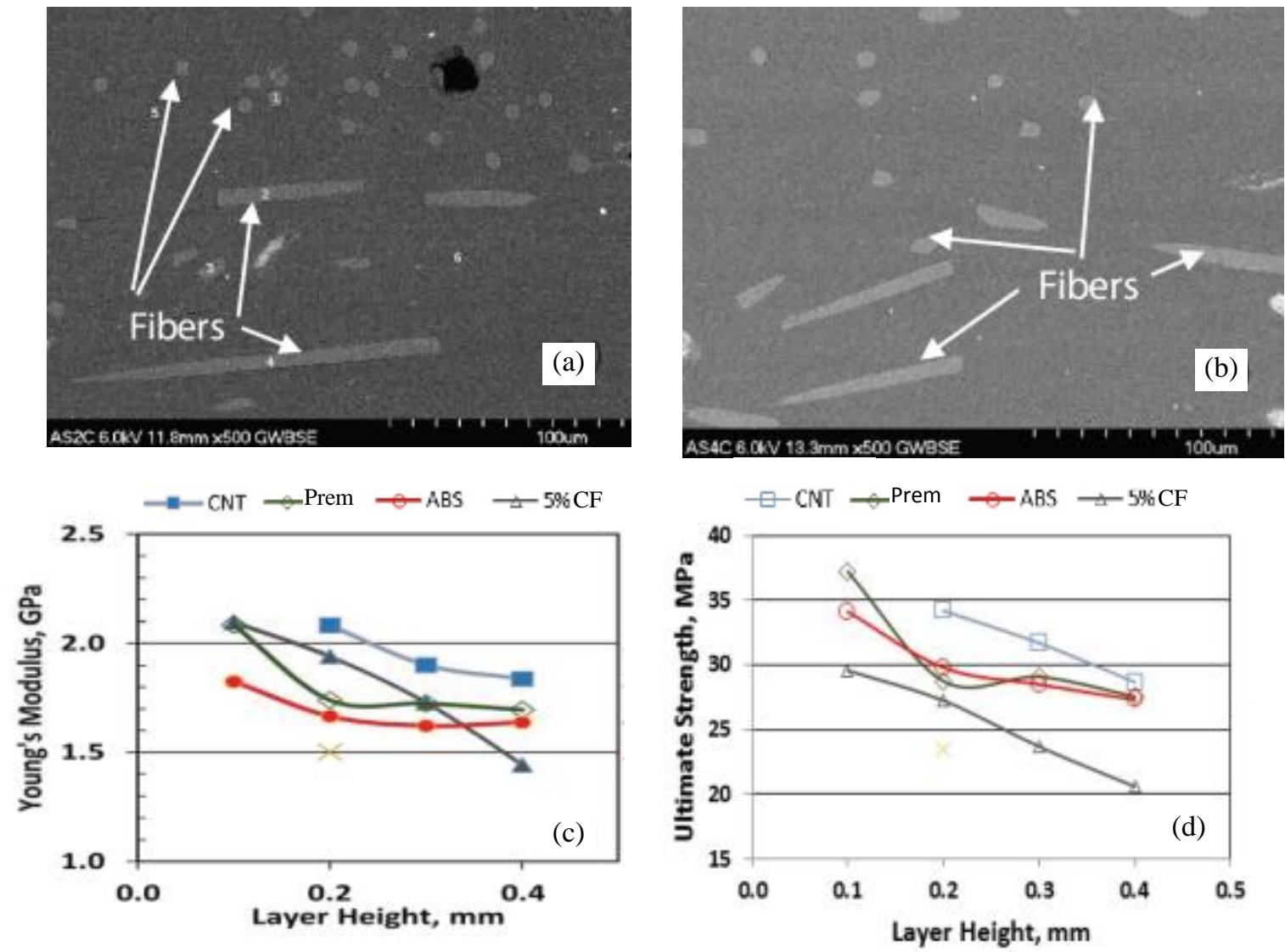

Figure 3 (c, d). 

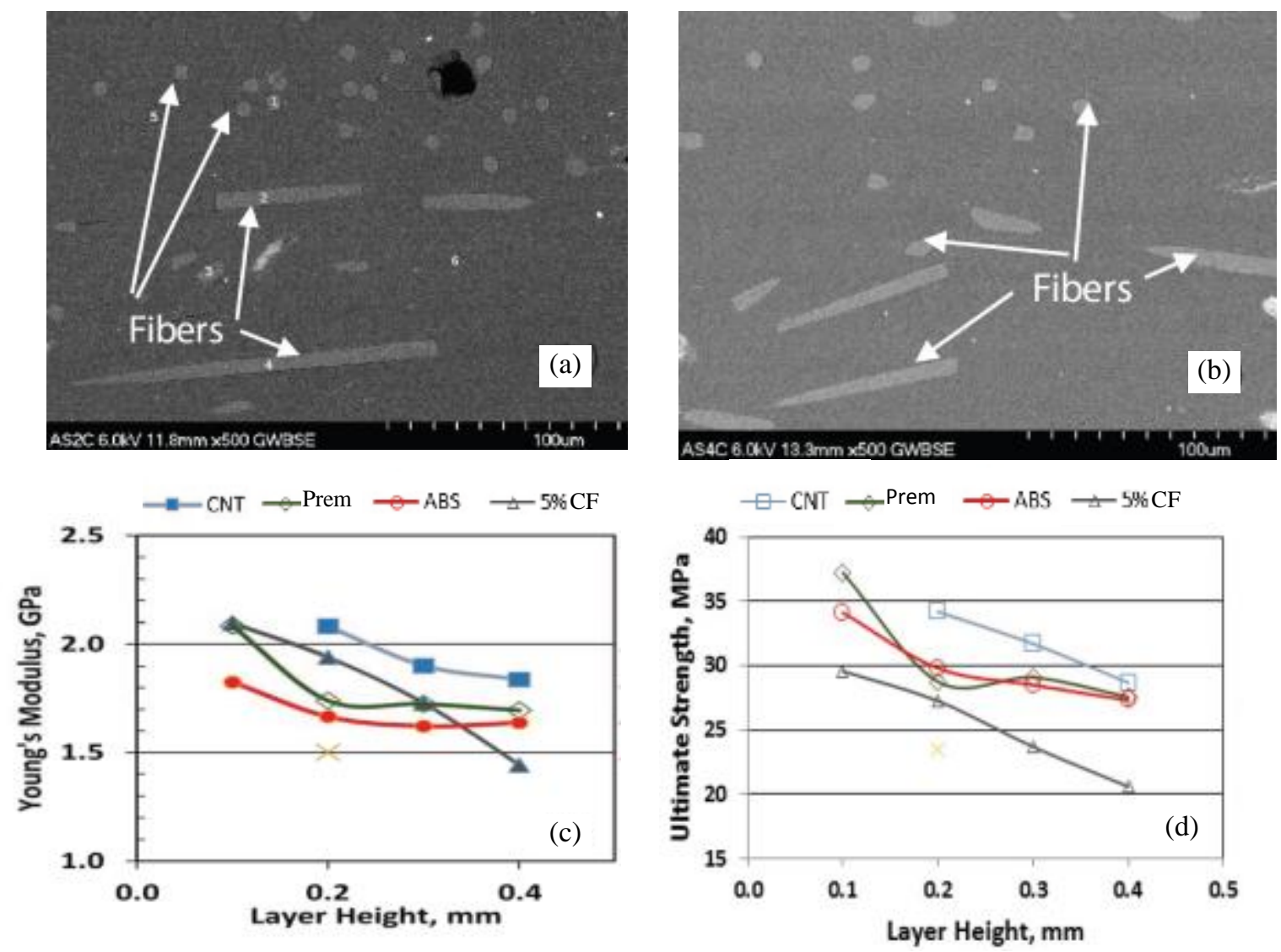

Figure 3: (a) SEM images carbon fibre distribution in $0.2 \mathrm{~mm}$ layer thickness, (b) SEM images carbon fibre distribution in $0.4 \mathrm{~mm}$ layer thickness, (c) Elastic modulus as a function of layer height, (d) Maximum strength as a function of layer height ${ }^{[70]}$, with kind permission from Wiley. 
Vapor-grown carbon fibre (VGCFs)/ABS nanocomposite was developed to fabricate improved filaments for FDM. The nanocomposite filaments were prepared by Banbury mixing, and extrusion prior FDM processing, see

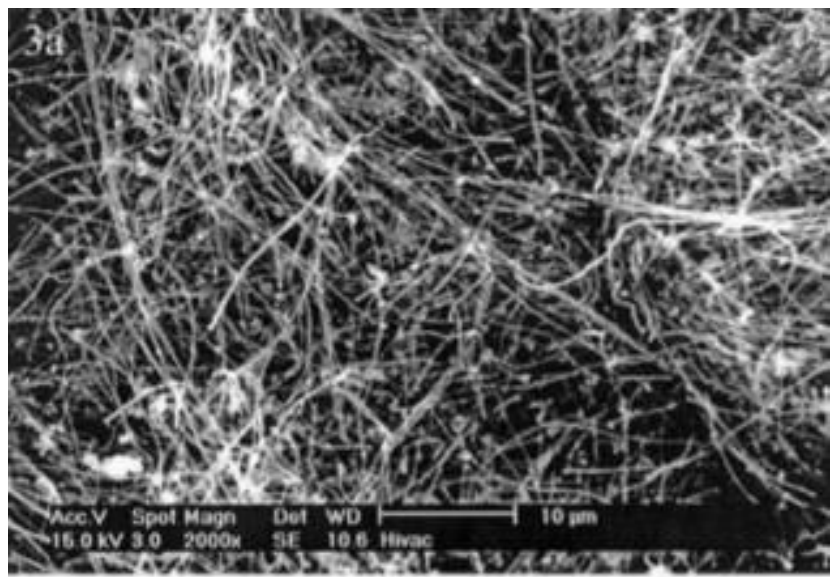

Figure 4. The VGCFs showed a good dispersion in the ABS matrix with minimal porosity. An improvement in the mechanical strength was noted for the developed VGCFs/ABS samples suggesting that the VGCFs provided additional strength and stiffness and changed the fracture from ductile to brittle ${ }^{[71]}$.

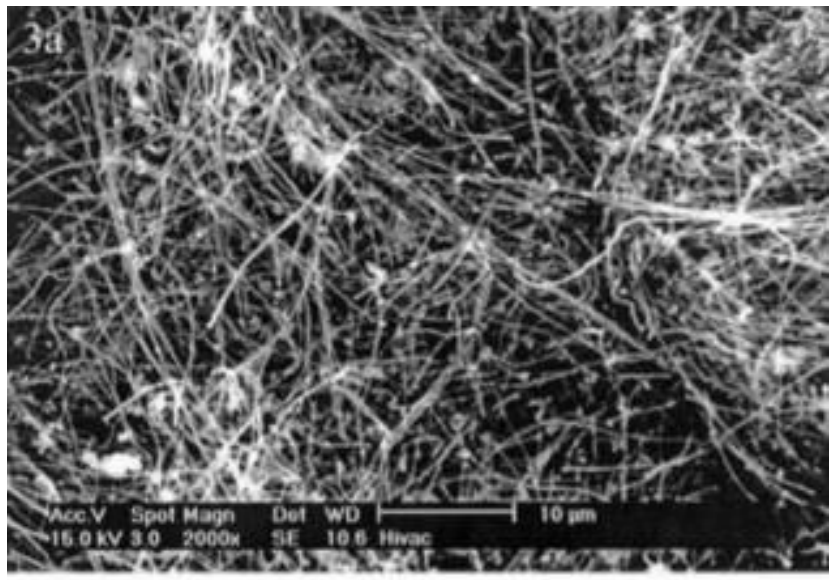

Figure 4: SEM images of the VGCFs ${ }^{[71]}$, with kind permission from Wiley. 
In an extensive study, Fuda et al. ${ }^{[72]}$ developed and characterised carbon fibre (CFRP) reinforced thermoplastic filament. The authors added CFRP with different length and content into ABS matrix aiming to improve the mechanical properties of the composite filaments. In their study, they characterised the tensile and flexural strengths, Young's and flexural modulus, ductility and toughness. They concluded that, the addition of CFRP into ABS improved the ultimate strength, Young's modulus, flexural stress, flexural modulus, and toughness but reduced the yield strength and ductility. The fractures surface of the samples showed that the applied load was transferred uniformly from the ABS to the CFRP, achieving better mechanical properties ${ }^{[72]}$. However, the 3D printer' nozzle was often clogged with composite made from higher carbon fibre content $(40 \mathrm{wt} \%)$ and length $(3.2 \mathrm{~mm}){ }^{[73]}$. In a similar study, CFRP was also investigated in a PLA matrix. The developed CFRP/PLA samples have six times higher strength than pure PLA ${ }^{[74]}$. Similar results were also obtained with the use of glass fibre ${ }^{[75]}$.

\subsubsection{Ceramic and Metallic FDM}

Fused deposition modelling of ceramics, also abbreviated as (FDC) technique is developed to manufacture net shape ceramic parts. In this technique, filaments are fabricated from a mixture of thermoplastic polymer and ceramic materials ${ }^{[76]}$. The process is followed by a debinding and sintering post processes to remove the polymer material and densify the ceramic powder. Therefore, the part design and the process parameters have to be adapted to predict the shrinking of the samples after sintering. Different advanced ceramic materials were successfully developed for FDC. Silicon nitride samples were introduced by Iyer et al. ${ }^{[77]}$. Powder processing was used to mix the $\mathrm{Si}_{3} \mathrm{Ni}_{4}$ particles with wax as a thermoplastic polymer. Next, the mixture was extruded to produce the filaments and the printed samples were sintered to achieve full density $\mathrm{Si}_{3} \mathrm{Ni}_{4}$ parts. Elongated $\beta-\mathrm{Si}_{3} \mathrm{Ni}_{4}$ was found in a boundary of 
glass phase. It was also clear that there was no inter-lamellar or inter-laminar inhomogeneities see Figure $5^{[77]}$.

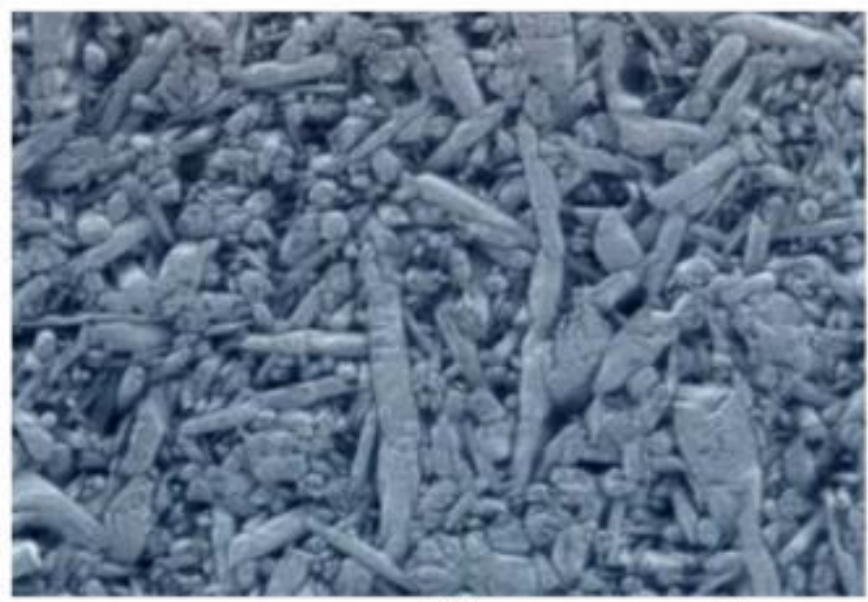

(a)

$10 \mu \mathrm{m}$

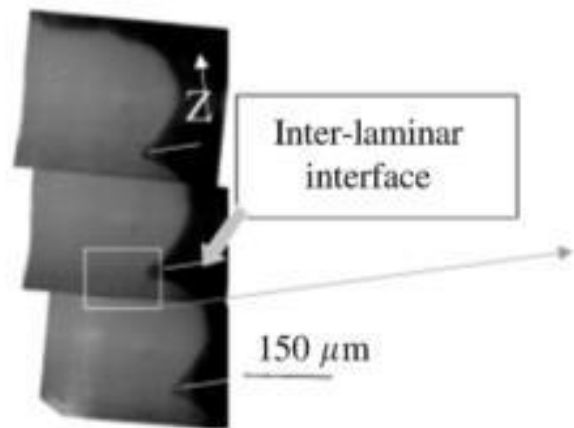

(b)

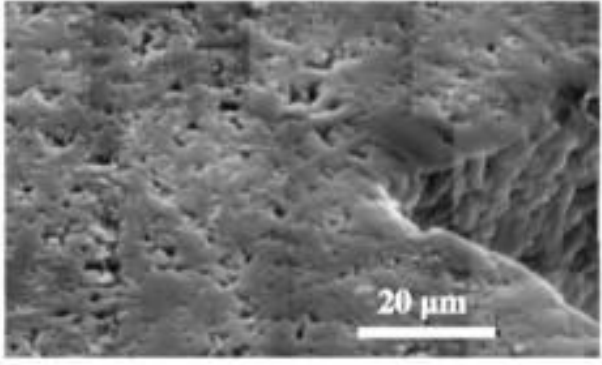

(c)

Figure 5: (a) SEM image of the sintered $\mathrm{Si}_{3} \mathrm{~N}_{4}$ fabricated by FDC, (b) Optical micrograph the vertical direction, (c) Magnified SEM image of the inter-laminar region ${ }^{[77]}$, with kind permission from John Wiley and Sons.

Other ceramic materials include lead zirconate titanate, zirconia, alumina filaments were also prepared for FDC ${ }^{[78-80]}$. The same approach was also used to generate FDM metallic parts ${ }^{[81]}$. Here, the polymer is used as binder and mixed with stainless steel powder followed by a debinding and sintering process to achieve the metal component. 


\subsection{Properties of FDM Parts}

Properties of FDM parts depend on material, design, and process parameters. The most important parameters among them are: the build direction, the toolpath of the design parameters, and the temperature of the nozzle and parameters of the heated bed during the printing process. The build direction and the tool path define properties of the extruded filaments during the process. Hence, FDM parts show anisotropic properties. The extruded filament width, layer thickness and the spacing between the extruded filaments are particularly important, not only for affecting the mechanical properties but also the surface roughness, geometrical tolerance and resolution of the FDM parts. The direction of the extruded filament plays an important role in defining the mechanical properties. Higher strength of the material is typically achieved when the extruded filaments are in the same direction as the applied load. On the other hand, lower strength is expected when the load is perpendicular to the layers or the extruded filament direction due to the risk of de-lamination. Sood et al. ${ }^{[82]}$ studied the effect of five process parameters on the compressive strength of ABS materials. These parameters are build orientation, raster angle, layer thickness, spacing between the extruded filaments and raster width. The results confirmed the anisotropic properties of the printed ABS. A maximum compressive strength of about $17 \mathrm{MPa}$ was achieved by optimising the process parameters. In addition, a good prediction of in-plane stiffness and strength can be obtained via Classical Lamination Theory (CLT) and Tsai-Hill yielding criterion. Those theories were originally used to mathematically describe fibrereinforced plastics. However, it was found that they were also applied to FDM ${ }^{[83]}$. Surface roughness is another important property of FDM parts. FDM products are typically having ridges along their surface, also known as the stair stepping, which were resulted from the deposited layers. Therefore, poor surface roughness is considered as one of the drawbacks of FDM. Stair stepping effect can be minimized by using thin layers. However, there is a 
technical limitation in reducing layer thickness. In addition, reducing layer thickness increases the production time. On the other hand, surface orientation plays an important role in controlling surface roughness. In general, lowest surface roughness is typically found in horizontal surfaces while it is the greatest for vertical or inclined surfaces ${ }^{[84]}$. Kaji and A.Barari ${ }^{[85]}$ introduced a model to predict the surface roughness of FDM parts. The model can be used to optimise the process parameters such as part direction and layer thickness to obtain AM parts with a required surface roughness. To minimize the stair stepping effect, Hai-Chuan Song et al. ${ }^{[86]}$ used a novel algorithm to control the layer thickness by introducing a sub-layer in z-direction to improve sloped surfaces. In this technique, the sub-layer information is first used to create curved tool paths that represent the input CAD geometry with better quality. Next, a slicing strategy is carried out to produce non-flat layers, which does not exceed the minimum thickness threshold. Finally, the tool paths are split and ordered to eliminate the nozzle interference during printing between adjacent paths of dissimilar heights.

In

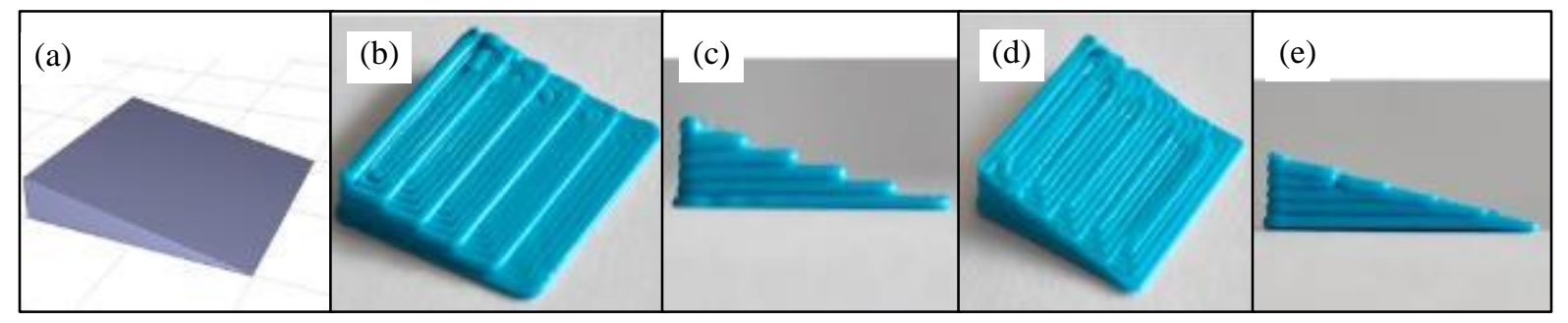

Figure 6 the impact of this anti-aliasing algorithm is shown for a simple part. However, with more advanced parts, the complexity for the algorithm is increasing as well. 


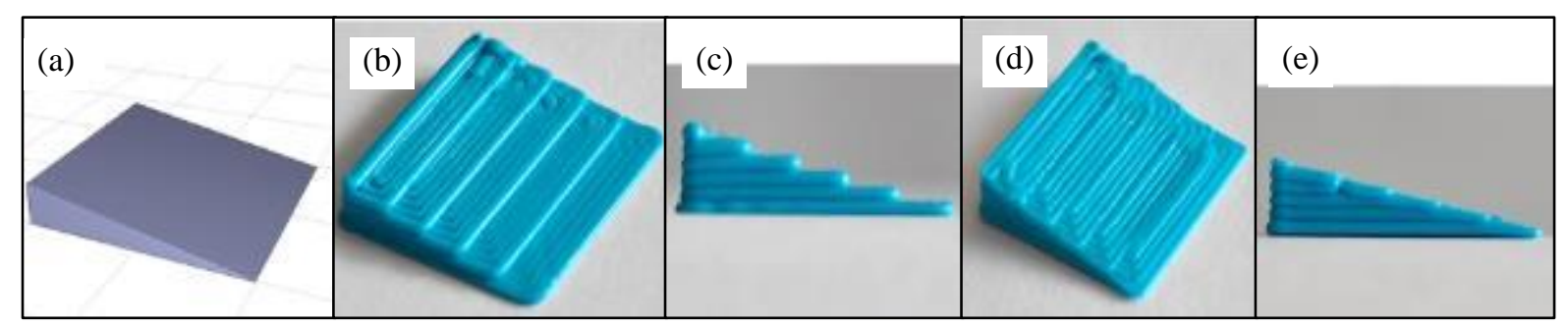

Figure 6: Anti-Aliasing Algorithm - a) STL-file b) isometric view and c) side view on part printed without algorithm; d) isometric and e) side view on part printed by using the antialiasing algorithm ${ }^{[86]}$, with kind permission from Elsevier. 


\subsection{Post-Processing}

Post processing is an important step for FDM because the printed parts are typically not suitable for immediate use. FDM parts are typically fabricated with a raft to promote the adhesion with the bed. In addition, support structures are also used to support over-hanged features. As a result, rafts and support structures removal is the first post-processing in any FDM process. Support structures can be either standard or dissolvable. Manual or mechanical removal of the support materials is carried out for mono material printers. Removing of standard supports is typically effortless. However, in some cases, it is difficult to reach places such as small holes to remove their support. Therefore, proper support design and placement are critical for successful FDM. On the other hand, chemical leaching is used to remove dissolvable supports by placing the printed parts in a bath with a solvent ${ }^{[87]}$.

After support removal, sanding is typically used to smooth FDM parts from supports marks. In some cases, warming FDM parts before sanding can improve the process. The process is not only important to polish rough surfaces but also to promote the adhesion of further coating or painting ${ }^{[88]}$. Conventional techniques such as milling, drilling, and turning can be also used as post processing techniques to improve surface quality, geometrical tolerance, and support removal. Resin infiltration is another technique to improve the properties of FDM parts by infiltrating them with a resin. This method can reduce the surface roughness by coating the ridges of FDM surfaces with a resin material ${ }^{[89]}$. Furthermore, surface improvement of ABS parts can be realized using a bath of Acetone vapour. Using this technique, surface roughness 
of ABS parts was significantly enhanced by $95 \%{ }^{[90]}$.

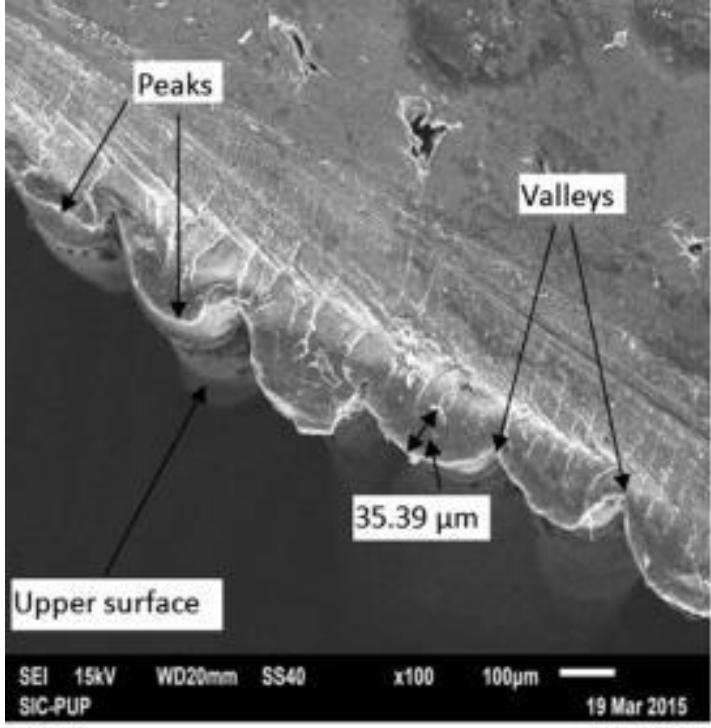

(a)

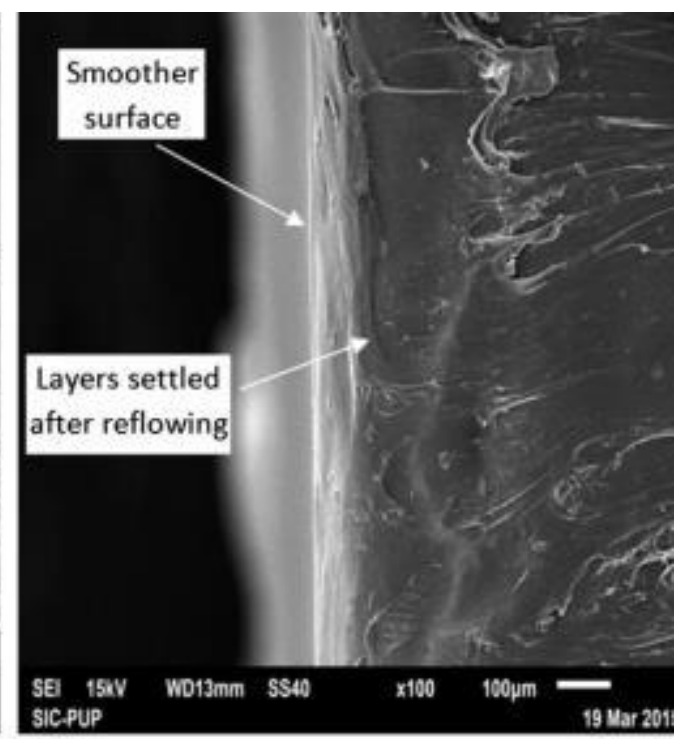

(b)

Figure 7 shows a comparison between ABS sample before and after post processing with acetone vapour bath. Hereby, the optimum smoothing procedure was carried out with duration of 30 seconds cycles following repeated precooling-smoothing-postcooling cycles to achieve improved surface finish ${ }^{[91]}$. Electro-plating is a technique where an electric current is used to plate an electrode with a thin metal layer. Electro-plating FDM parts with a thin metal layer were used to produce a metal/Polymer sandwich. As a result, functional components with higher strength and improved surface roughness were achieved ${ }^{[92]}$. 


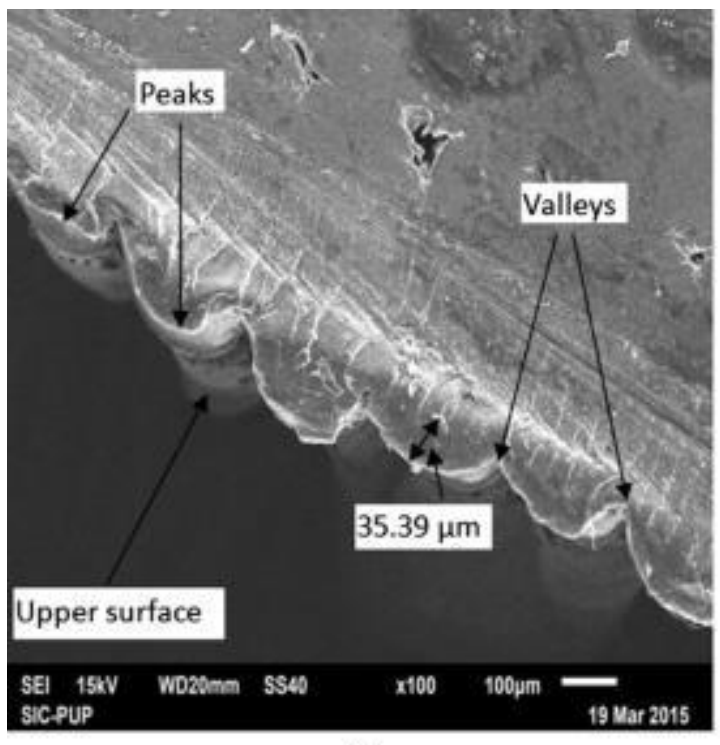

(a)

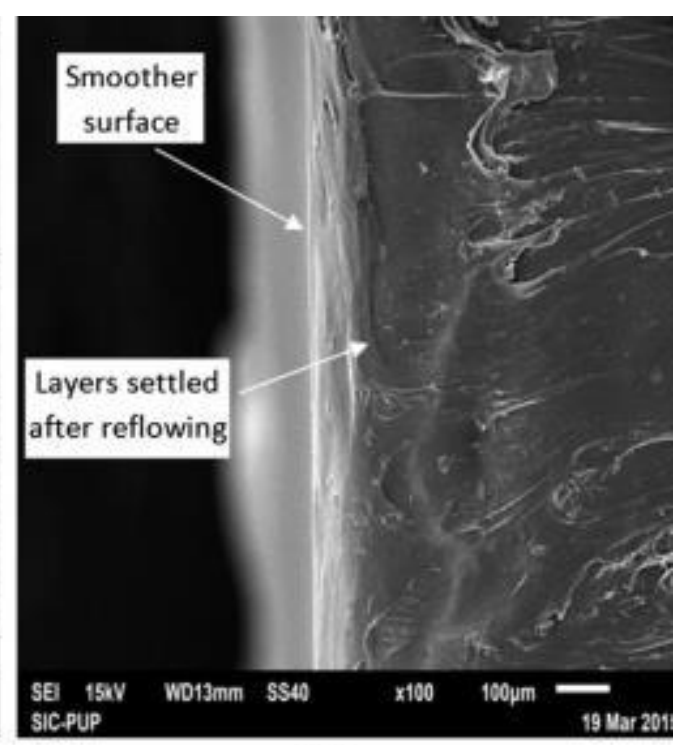

(b)

Figure 7: Scanning electron microscope images of an ABS sample (a) without Actone vapour smoothing (b) after smoothing ${ }^{[91]}$, with kind permission from Elsevier.

\section{Successful Applications of FDM in the UAVs Industry}

This section discusses the use of FDM as a reliable AM tools to fabricate UAV systems and their parts. It also discusses how FDM improves the structural, aerodynamic, and performance of UAVs.

\subsection{Structure}

FDM is a well-established technology to create porotypes, which helped to drastically reduce design iterations and development steps not only for UAV systems but also for a wide range of applications. Another benefit of using FDM manufacturing is to improve the structural efficiency of UAV by increasing the strength/weight ratio. The classic use of FDM was found in printing prototypes for UAVs parts to be modelled inside a wind tunnel aiming to predict aerodynamics of the proposed designs. It was found that the use of FDM decreased the production time and improved significantly aerodynamics performance of UAVs. In addition, FDM proved to be quicker, more accurate, and cost effective compared to conventional manufacturing of materials such as carbon fibre, aluminium, or wood models. In addition, the 
complexity of the models can increase dramatically, with no impact on the production time. However, a post processing technique such as the removal of support structure, grinding and polishing is required to obtain reliable surfaces for aerodynamic models ${ }^{[93-96]}$. Apart from using FDM to build design models, fixed wing UAV was printed completely from ABS using FDM by the advanced additive manufacturing research centre of the University Sheffield ${ }^{[97]}$. A vertical take-off and landing UAV was developed at Istanbul Technical University ${ }^{[98]}$. The FDM parts are limited to the rotor tilting and engine nozzle mechanism and were printed with PLA. Those two projects represent the advantages of FDM technology and show that complex shaped parts can be built and tested within days.

In a partnership between Aurora Flight Sciences and Stratasys, the first jet engine UAV was printed using FDM of Polyetherimide (PEI) and Acrylonitrile Styrene Acrylate (ASA) parts,

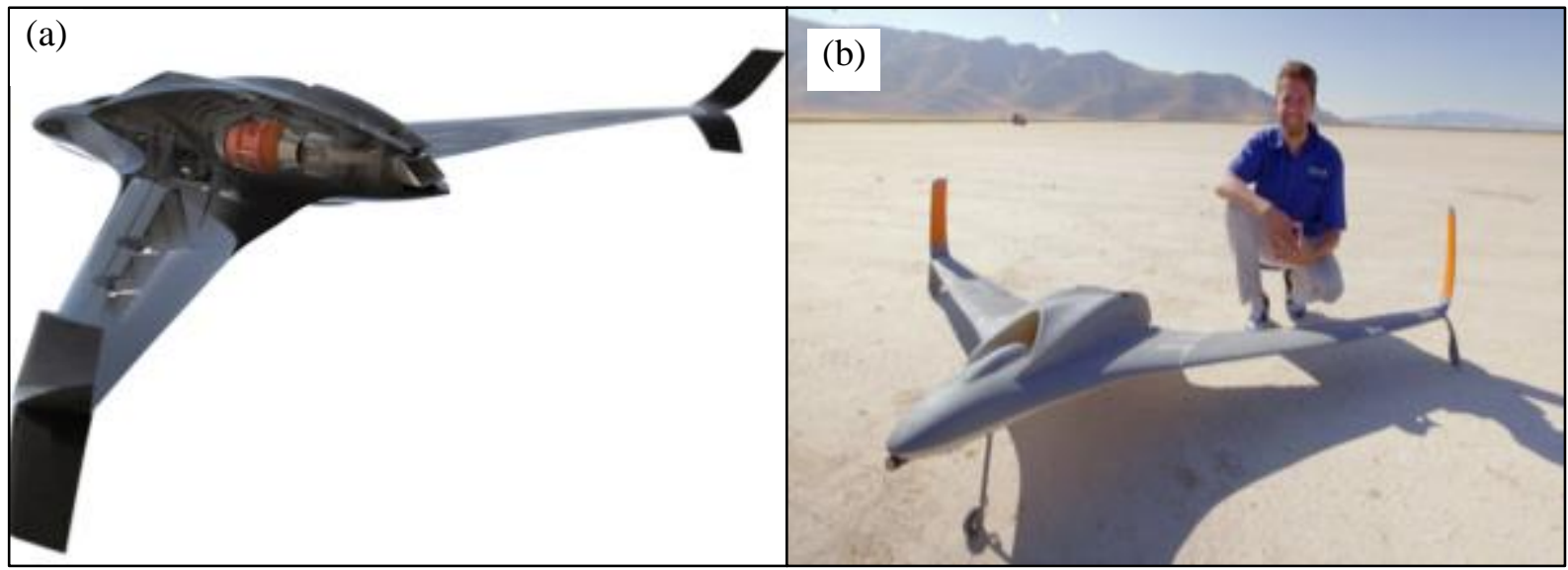

Figure $8^{[99]}$. Ultem ${ }^{\circledR}$, the trademark for PEI, is a certified material by the Federal Aviation Administration (FAA), USA. In this project, $80 \%$ of the UAV was built using AM. Although the majority of the parts were built using FDM, other AM technologies such as laser sintering were also used to build Jet engine outlet. The $2.75 \mathrm{~m}$ wingspan of the developed UAV was capable of flying with a speed of $240 \mathrm{~km} / \mathrm{h}$, which makes it the fastest FDM printed UAV. 
The material has been also used to produce parts for commercial aircrafts such as the Airbus $\mathrm{A} 350^{[99]}$.

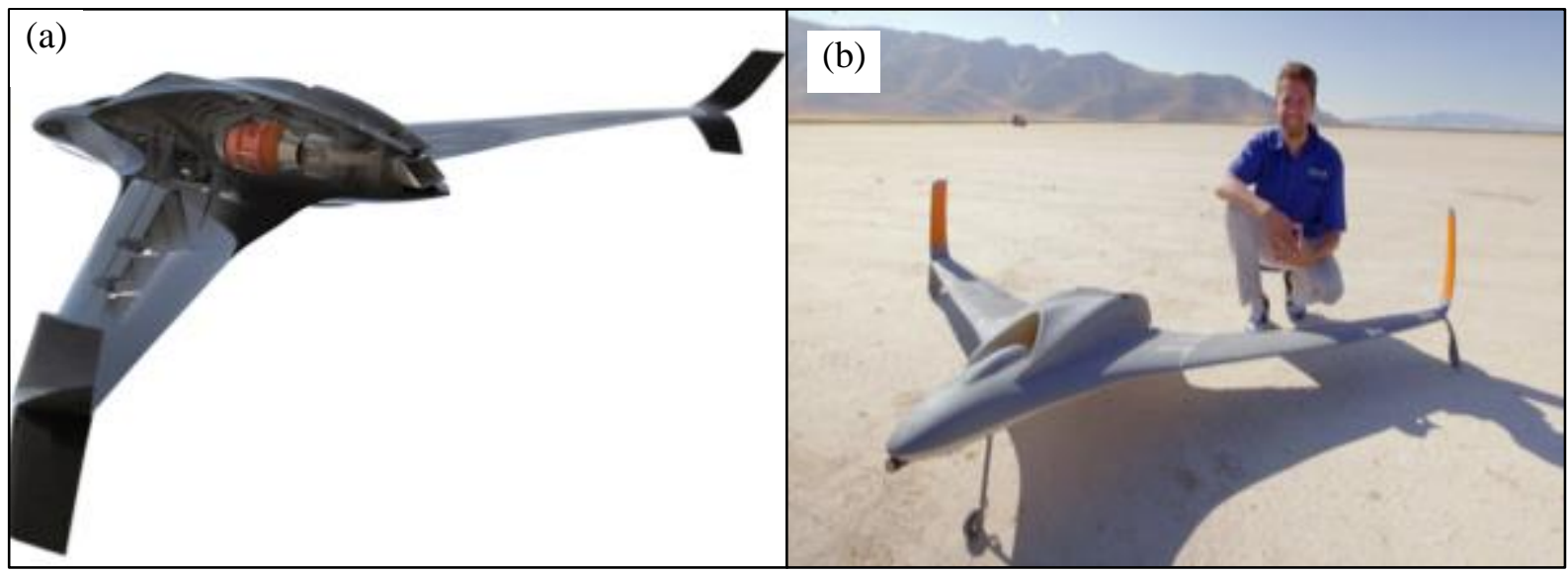

Figure 8: FDM printed jet engine UAV a) CAD model - Jet engine in red and transparent wing section to show the infill, b) Printed UAV used for successful flight test ${ }^{[99]}$, with kind permission from Stratasys.

Another project between Aurora Flight Sciences and Stratasys was the development of X-

Plan, a vertical take-off and landing UAV, using carbon fibre and FDM technology. In this

UAV, the manufacture complexity increases dramatically as the electric fan engine was

integrated with the wings. In addition, the wings and the canard can be tilted to allow the vertical take-off and landing (VTOL) functionality. The wings were split into hollow 
structures as shown in

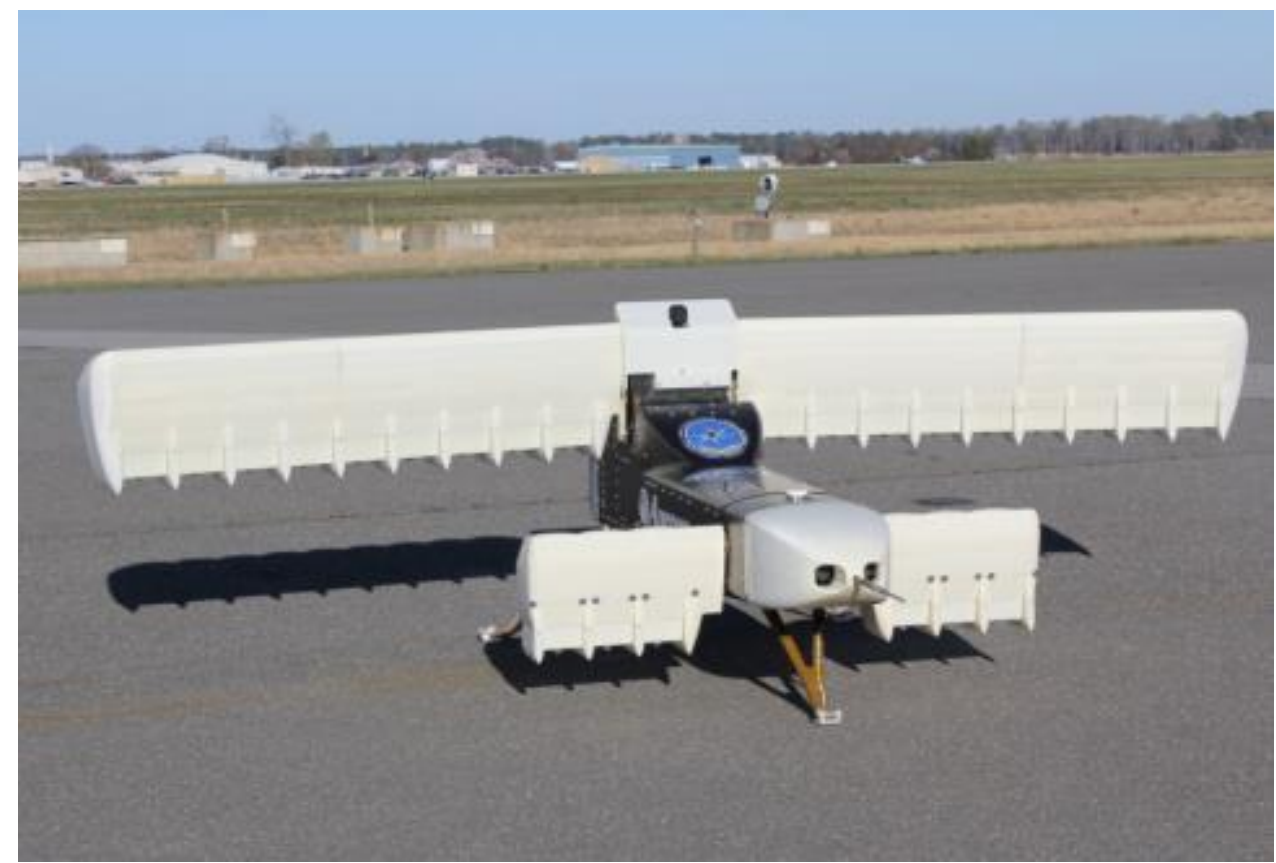

Figure 9. Hence, 24 engine nacelles were designed within in-wing motor compartments ${ }^{[100 \text {, }}$ 101].

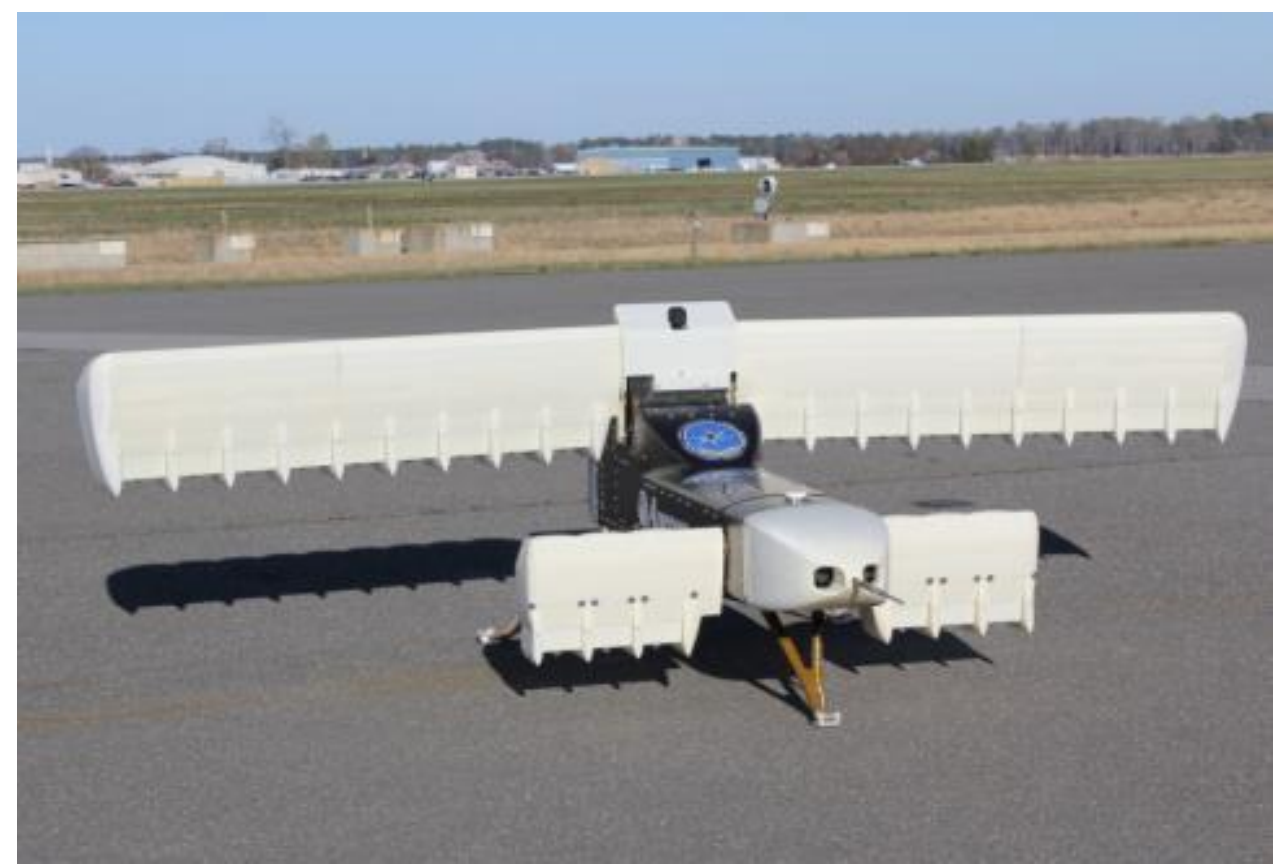

Figure 9: Aurora - XV-24A Lightning Strike flight test miniature model ${ }^{[102]}$, distribution unlimited. 
At the MIT Lincoln Laboratory, M. Stern and E. Cohen ${ }^{[103]}$ designed and built the Variable AirSpeed Telescoping Additive Unmanned Air Vehicle (VAST AUAV) for atmospheric sensing from ABS by using FDM. The developed UAV was built with a lightweight structure, allowing optimum aerodynamics, and meets performance targets. Telescoping wings were used to allow loiter and dash flight depending on both aerofoil and expanded wing. The length of the wingspan was $2 \mathrm{~m}$ and the total weight of the UAV was $3.2 \mathrm{~kg}$. The design of the UAV allows an easy assembly by using standard tools. Successful test flights were conducted revealing the structural integrity of the FDM parts ${ }^{[103]}$.

Hobbyists were also contributed in the development of small fixed wing UAVs using FDM since $2013^{[104]}$. Within this community, many designs, manuals and tips are available for home print UAVs ${ }^{[105]}$, thanks to the development of the FDM technology that allowed producing fully operational UAVs capable of competing commercial models. A. Neathery ${ }^{[106]}$ built a support structure frame for a quadcopter UAV and released the open source files online. In addition, U. Peter ${ }^{[107]}$ published a Star Wars inspired tie fighter, flying as a multirotor UAV. Furthermore, the filament company Fibre Force Italy printed a UAV model from carbon fibre reinforced nylon. The used filament has a tensile strength of $100 \mathrm{MPa}$ and a modulus of elasticity of $6000 \mathrm{MPa}^{[108]}$.

\subsection{Embedded electronics}

UAVs are typically carry electronic equipment and sensors. Hence, embedded electronics are important items in the design of UAVs and have been under investigation by several researchers. In one study by Gardner et al. ${ }^{[109]}$, the thermal and electric conductivity of thermoplastic polymers were improved using CNT nanocomposite, see Figure 10. As shown in the figure, the filament material was prepared using CNT dispersed into Polyetheriminde (PEI) matrix material. The tensile strength of the developed filament was increased from $89 \pm$ $7 \mathrm{MPa}$ to $112 \pm 4 \mathrm{MPa}$ with the addition of 4.7 wt. $\%$ of CNT. Additionally, CNT improved 
the electric conductivity of PEI and the electric current was successfully transferred in the printed FDM samples. Using a two nozzle FDM printer, the UAV frame was successfully printed using CNT/PEI filament. All the four motors of the UAV were supplied with current using the printed nanocomposite ${ }^{[109]}$, as shown in
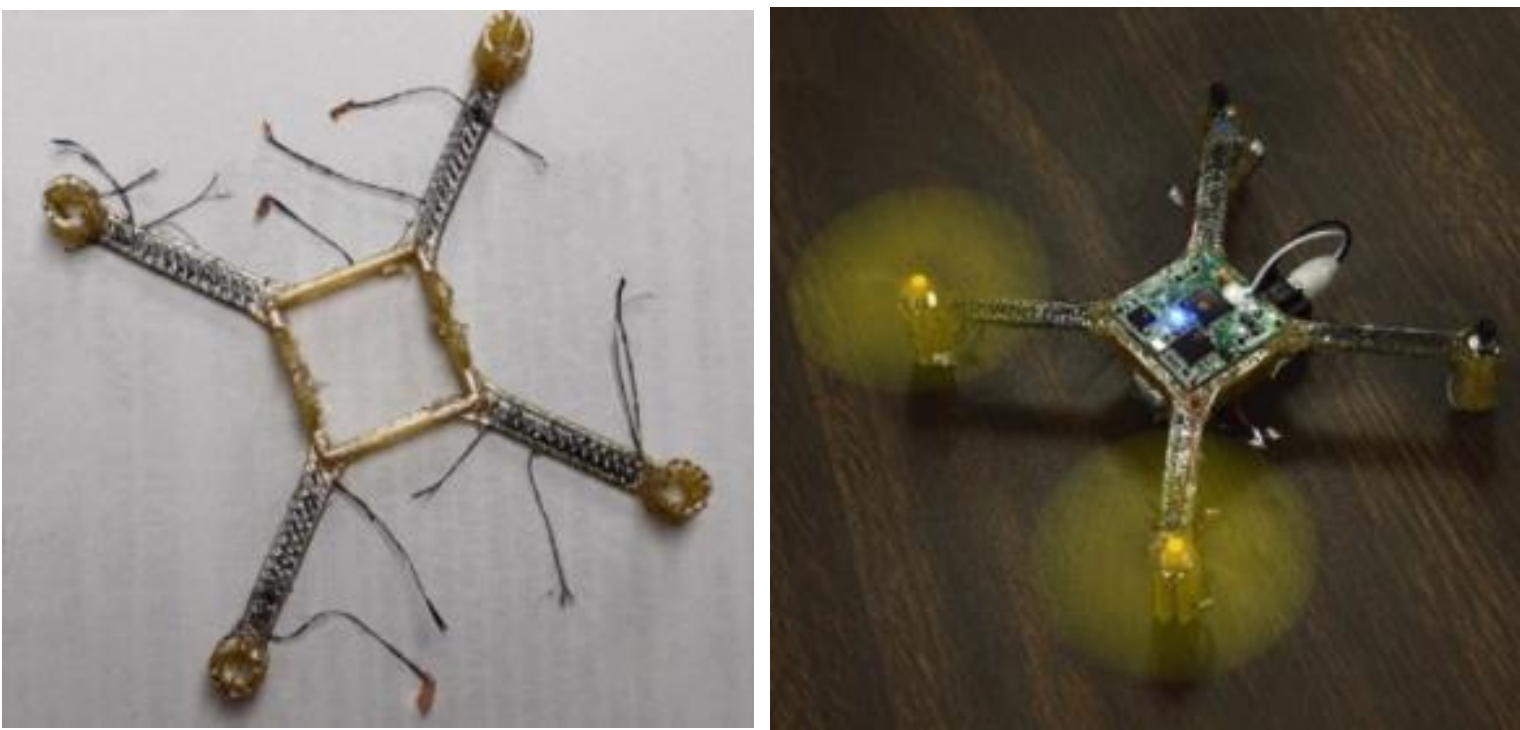

Figure 11.

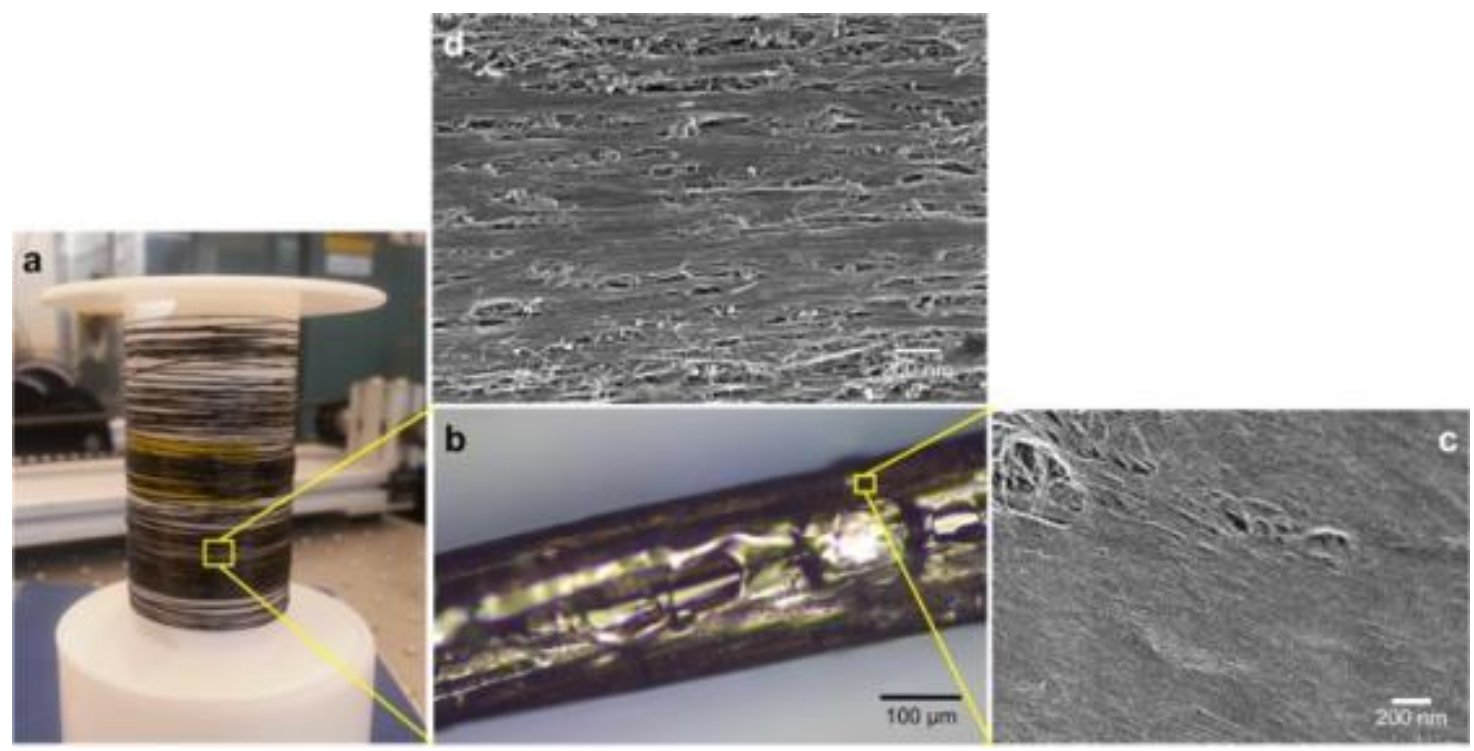

Figure 10: (a) A spool of CNT nanocomposite filament, (b) Optical microscopy image of individual filament, (c) SEM image of CNT nanocomposite filament, (d) SEM image of printed sample ${ }^{[109]}$, with kind permission from Elsevier. 

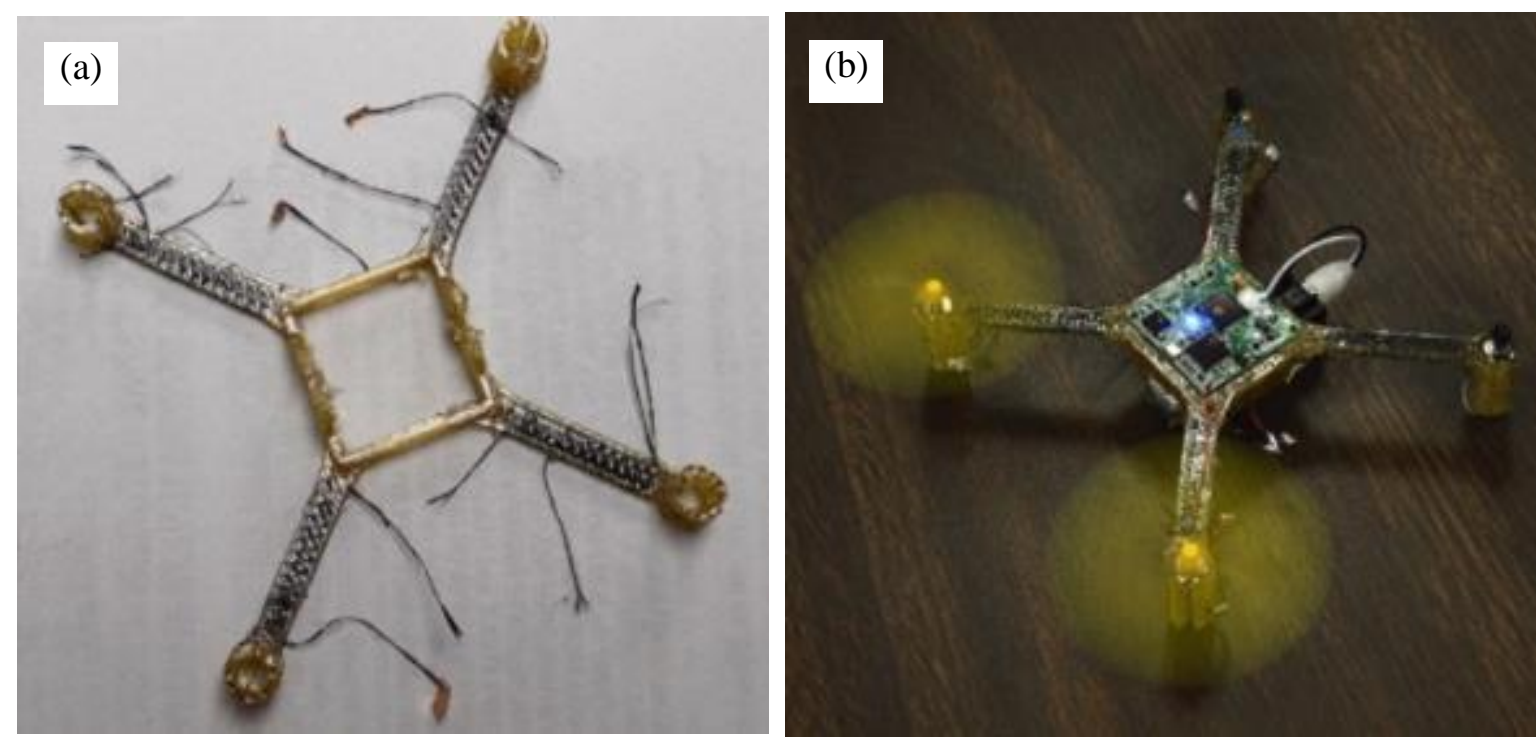

Figure 11: (a) PEI nanotube in PEI frame (b) CNT wire functionality test ${ }^{[109]}$, with kind permission from Elsevier.

Another study was conducted by Stratasys and NTU Singapore to build a quadrocopter capable of carrying over $60 \mathrm{~kg}$, with all electronic components fully embedded. The electronics were embedded in the UAV frame during the FDM process using Stratasys Ultem. The embedded electronic survived the high printing temperature which was about $160^{\circ} \mathrm{C}$ and only the propellers and the motors were assembled after building the frame. This UAV was completely printed in less than 14 hours ${ }^{[99]}$.

A summary of the available research projects that used FDM in the development of UAV is shown in Table 3. The printers were mostly used to manufacture wing profiles and body frames with integrated features. Slender wings profiles are often supported with an additional central wing beam. It can be noted that ABS is the most used material for small sized UAV. This may be because ABS is a sufficiently strong, low cost and easy to print. In addition, most of commercial printers have small beds, which are suitable for small sized UAV. More complex and larger UAVs often use PEI filaments, as they are the strongest and stiffest material among the available thermoplastic filaments. The use of CNT nanocomposite filaments showed promising results with UAV as a strong and conductive material. 
Table 3: Overview of FDM technology used for UAVs

\begin{tabular}{|c|c|c|c|}
\hline UAV Type & Components & Material & References \\
\hline $\begin{array}{l}\text { Fixed wing wind tunnel } \\
\text { models }\end{array}$ & Wing profile & ABS & [141] \\
\hline $\begin{array}{l}\text { Fixed wing variable } \\
\text { airspeed }\end{array}$ & Wing profile & ABS & [103] \\
\hline Fixed wing - deltawing & Frame & $\mathrm{ABS}$ & [97] \\
\hline Fixed wing - deltawing & Frame & ABS & {$[142]$} \\
\hline $\begin{array}{l}\text { Quadrocopter - Spare } \\
\text { parts }\end{array}$ & Body, arm, landing gear, etc. & ABS & {$[143]$} \\
\hline $\begin{array}{l}\text { Quadrocopter - Add on } \\
\text { parts }\end{array}$ & $\begin{array}{l}\text { Camera mount, protection } \\
\text { frame. }\end{array}$ & ABS & [144] \\
\hline Quadrocopter & Frame & CNT-Nylone & {$[108]$} \\
\hline VTOL fixed wing & Complex wing structure & PEI & {$[100,101]$} \\
\hline $\begin{array}{l}\text { Quadrocopter - } \\
\text { embedded electronic }\end{array}$ & Frame & PEI & [99] \\
\hline $\begin{array}{l}\text { Quadrocopter - Current } \\
\text { carring frame }\end{array}$ & Frame & $\begin{array}{l}\text { PEI-CNT } \\
\text { composite }\end{array}$ & [109] \\
\hline Fixed wing jet engine & Wing profile & PEI, ASA & {$[145]$} \\
\hline VTOL tilting mechanism & $\begin{array}{c}\text { Tilting brackets and engine } \\
\text { nozzle }\end{array}$ & PLA & [98] \\
\hline
\end{tabular}




\section{Potential and Challenges}

In general, the increased demand of FDM and noticeable cost reduction in its materials and printers has boosted the widespread of this technology in many fields. The wide range of materials and applications discussed in the present paper leads to a wide range of potentials that FDM holds for future UAVs. However, the use of FDM for niche applications such as UAVs is still in its proof of concept and there are many challenges to be overcome in order to implement the FDM technology as a productive and commercial tool. In this section, a discussion on the potential and challenges of FDM technique is presented.

\subsection{Potential}

One of the most relevant reasons for FDM technique becoming so popular is that it is a cost effective production tool used by minimally trained users all the way up to research and industrial scale for manufacturing of customised products. Typically, manufacturing of customised products involves the use of CAD and conventional machining with all of its limitations, which restrict the range. The high geometrical freedom is the most important benefit of FDM over the classical techniques and offers manufacturing of complex shapes accurately with consistency with a short lead-time according to specific end-user requirements. Application of FDM Method of 3D Printed UAV offers a fabrication method for producing customised UAVs for versatile applications. In addition, it also allowed design freedom of aerodynamics and structural prototypes for UAVs and aerospace applications. In particular, FDM manufacturing process was a key factor to accelerate wings and functional 
surfaces for aero and fluid dynamics, see

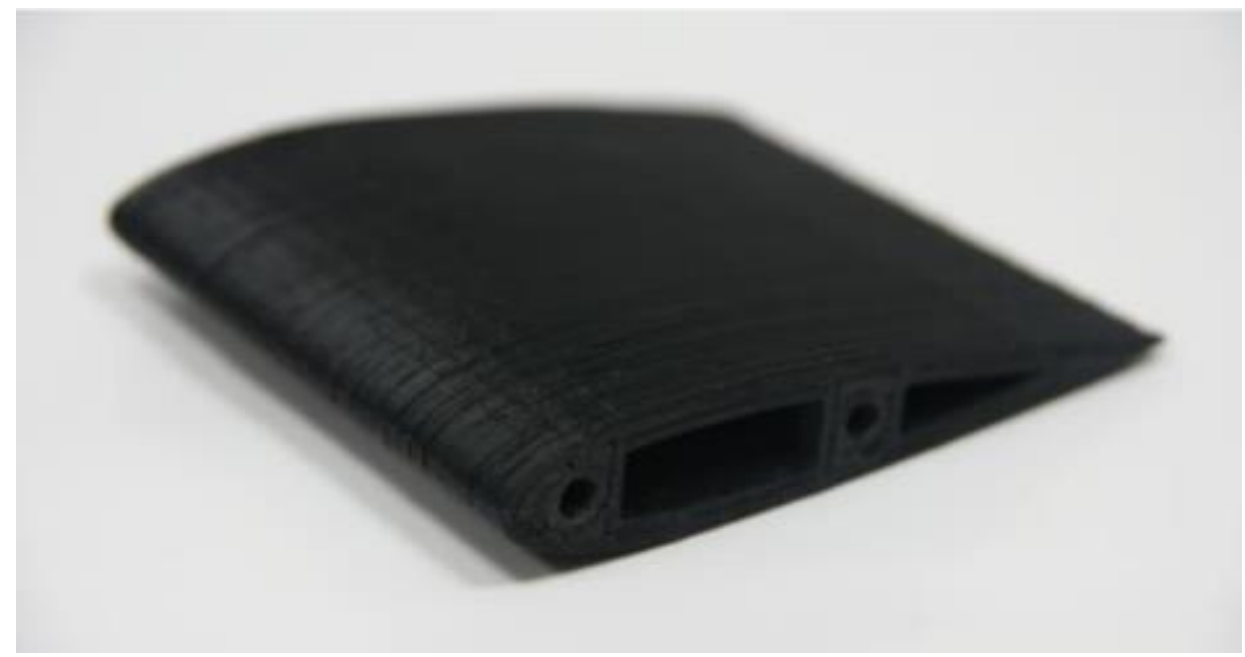

Figure $12^{[110]}$. By adopting FDM, it was possible to improve computational fluid dynamics, and validate the models experimentally using FDM parts in wind tunnels.

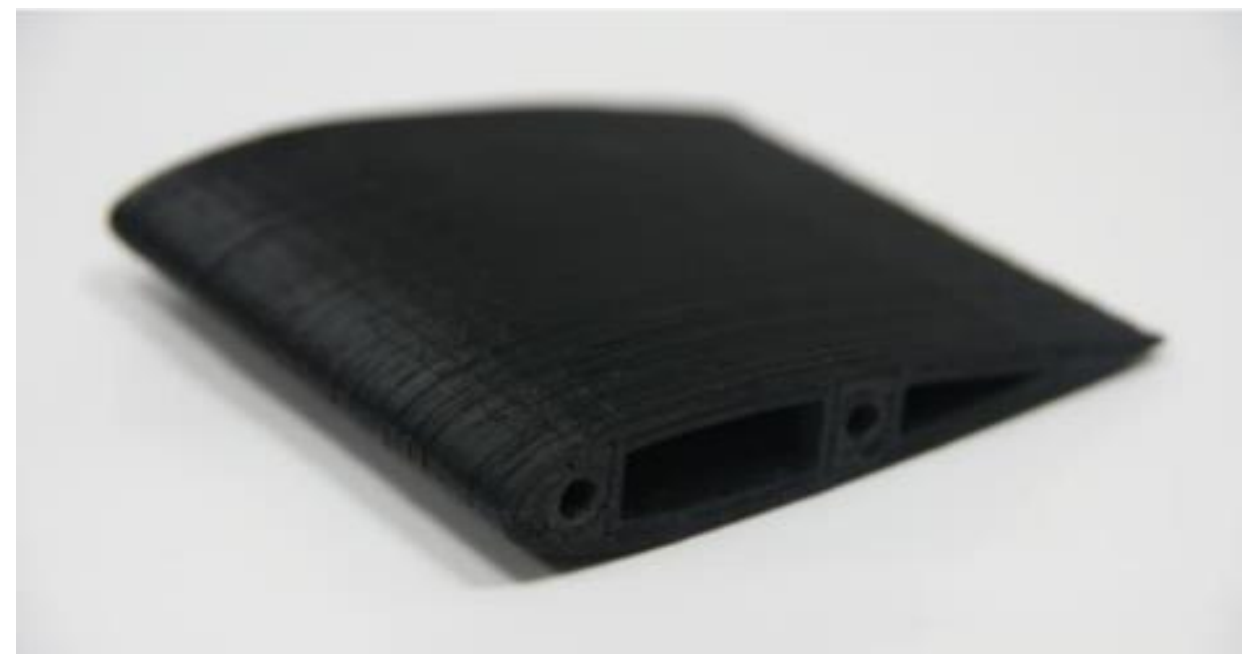

Figure 12: An Example of 3D printed aerofoil model using FDM ${ }^{[110]}$, Free to copy and redistribute.

FDM can manufacture parts with multiple materials in different regions of the object. Multimaterials FDM parts have been used in several products such as antennas and electroceramics ${ }^{[111,112]}$. Printing FDM parts with dissolvable support structure is a clear example of the use of multi-materials to realise a simplified support removal ${ }^{[87]}$. As explained, FDM has 
been with many materials such as metals, composites and nanocomposites. In most cases, it was possible to disperse ceramic, metal and fibres into thermoplastic polymers in order to improve the mechanical strength, stiffness, thermal and electrical conductivity of FDM parts. In addition, it is also possible to control the properties of FDM components by controlling process parameters, materials and build direction ${ }^{[63-66,68-72]}$. 
Metamaterials are manmade structured materials developed to manipulate physical phenomena such as sound, light, load and many others. Their unique properties are obtained from the original properties of their materials along with the geometry of their structures. Metamaterials with conductive properties such as embedded carbon nanotubes represents a drastic improvement in UAVs industry as it reduces the wiring on the aircraft and allows the integration of electronic components such as gyroscopes, accelerometer, barometer, and GPS within the frame. This improves the mass distribution on-board and therefore the aerodynamics of UAVs ${ }^{[109]}$. Auxetic materials is another type of metamaterials with negative Poisson' ratio that exhibit energy absorption, acoustic, and thermal properties that controlled by the geometry of the developed structures. These properties hold the potential for UAV structures with enhanced properties and the design freedom of FDM enables the fabrication of Auxetic structures for wide range of applications ${ }^{[113]}$, see

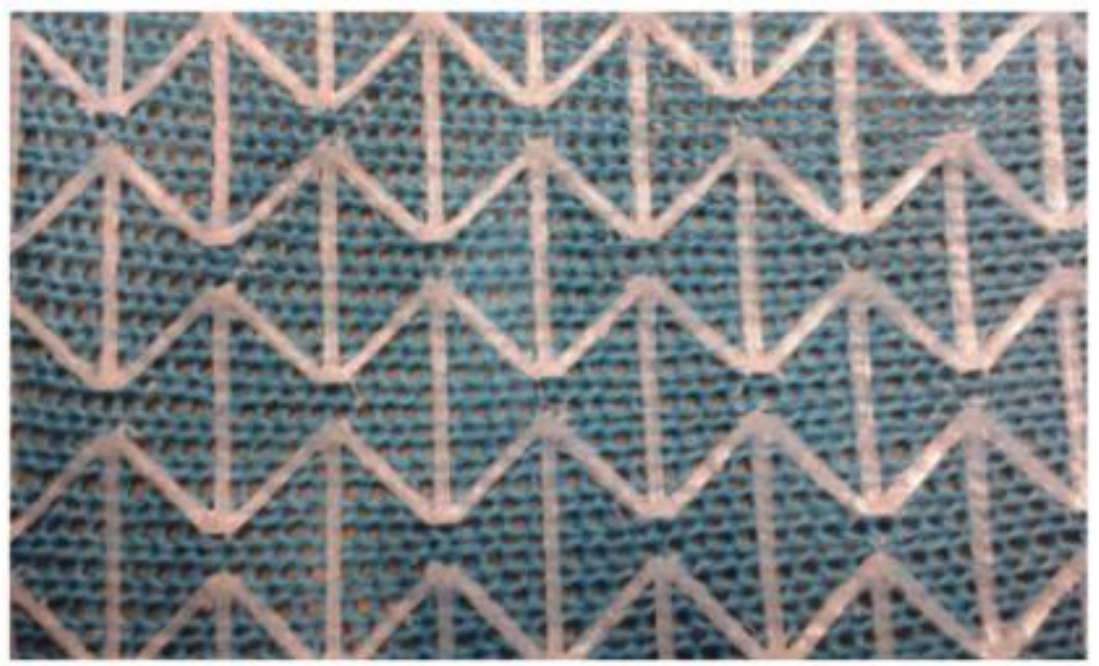

Figure 13. Furthermore, most of FDM printers can manufacture parts in colour. This has been achieved by using filaments with different colours for different part of the model. Printing in colours reduces some of the post processing steps such as coating or painting ${ }^{[114]}$. As a result, UAVs can gain many advantages of using multi-materials, composites, metamaterials, and 
multi-colours FDM. This includes producing more integrated and complex parts making this technology simple, fast, and practical with a wide range of materials and colours.

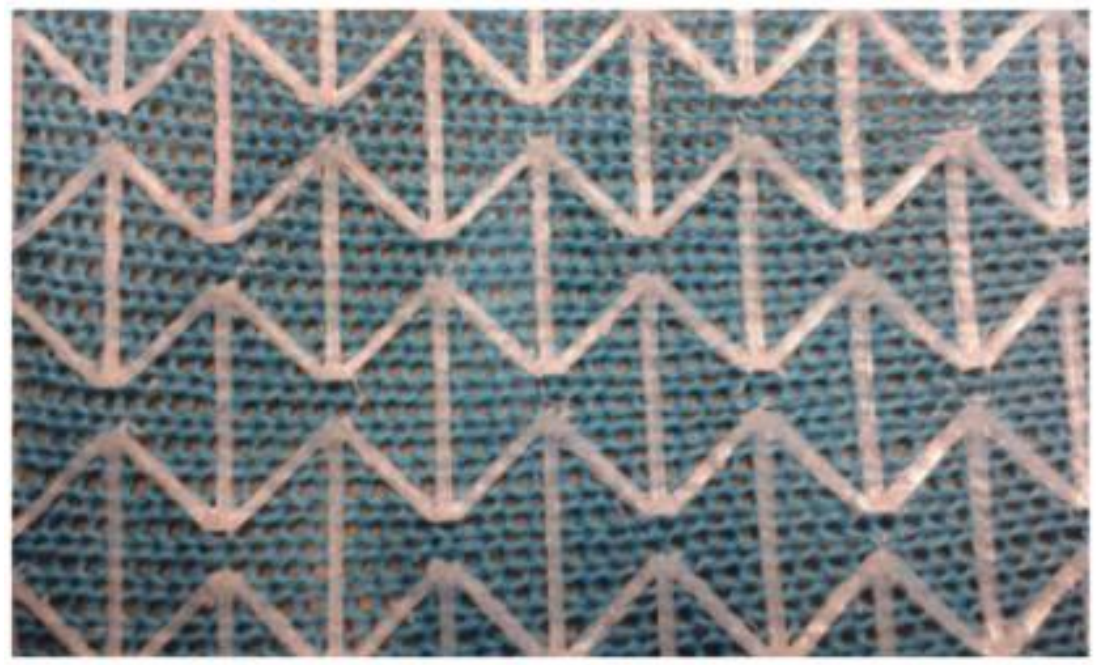

Figure 13: Auxetic structures by using FDM on a single-face fabric ${ }^{[113]}$, Free to copy and redistribute.

FDM allows the production of complex shaped internal geometries to enhance performance of the produced parts. It has been used to create channels, microfluidics, batteries, and scaffolds

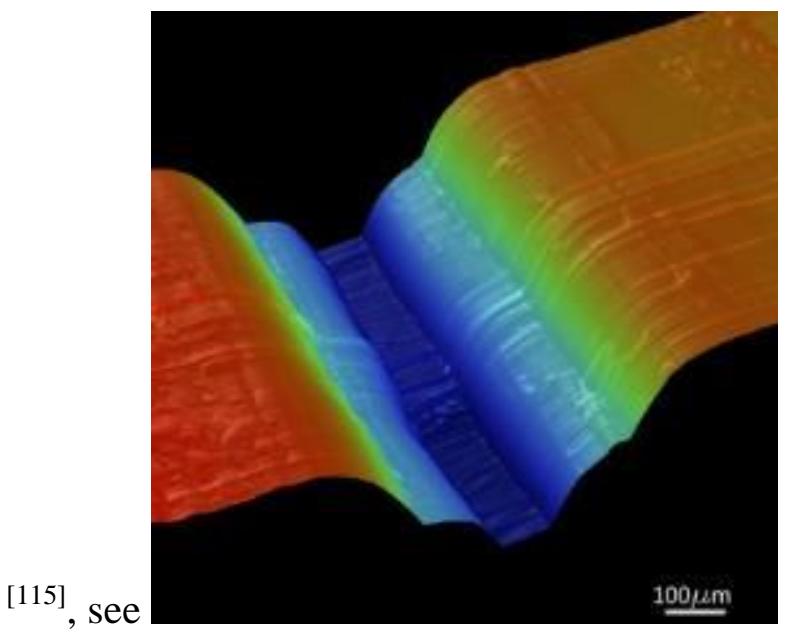

Figure 14. As shown, building internal features is very critical for UAVs. However, it is not an issue for FDM. Allowing geometrical freedom in building internal features enables the production of lightweight structures with improved aerodynamics and also allows the placement of embedded electronics ${ }^{[99]}$. 


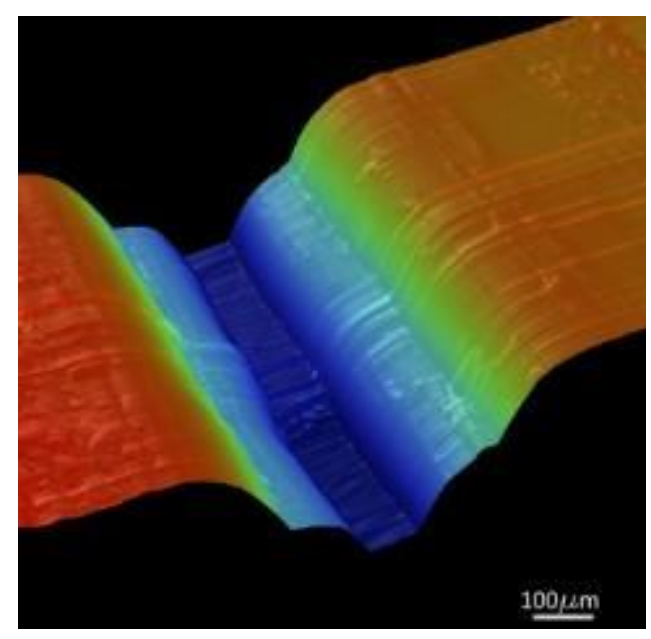

Figure 14: Cross-section perfilometry of an opened FDM PLA microchannel ${ }^{[115]}$, with kind permission from Elsevier.

FDM also allows topology optimized structures for lightweight and enhanced structures. Topology optimization is a structural optimization method for distributing part material according to the resultant stress and stiffness. Hence, the optimised design is improved in terms of reduced mass, improved stiffness, and in some cases enhanced factor of safety. With topology optimisation solutions, parts design becomes more and more organic and optimized according to the applied load. Therefore, it is particularly essential for automotive and aerospace applications where mass reduction is significant in material, energy and cost saving $[115,116]$. Because of the design freedom of FDM, it is anticipated that topology optimisation represents a potential boost for the UAVs technology, providing longer endurance aircrafts with larger payload capacity. The use of topology optimisation to improve UAV design application was carried at the University of Southampton using lightweight laser-sintered UAVs ${ }^{[117]}$. The results shows that FDM holds the potential to enable a low cost manufacturing of topology optimised UAVs parts, allowing a high operative range. Ferro et al. ${ }^{[118]}$ applied topology optimisation to reduce the weight of UAV components and to enhance the productivity of the FDM. The results showed that, FDM with applying an 
adequate topology optimisation was able to construct components with improved design for UAV systems,

(b)
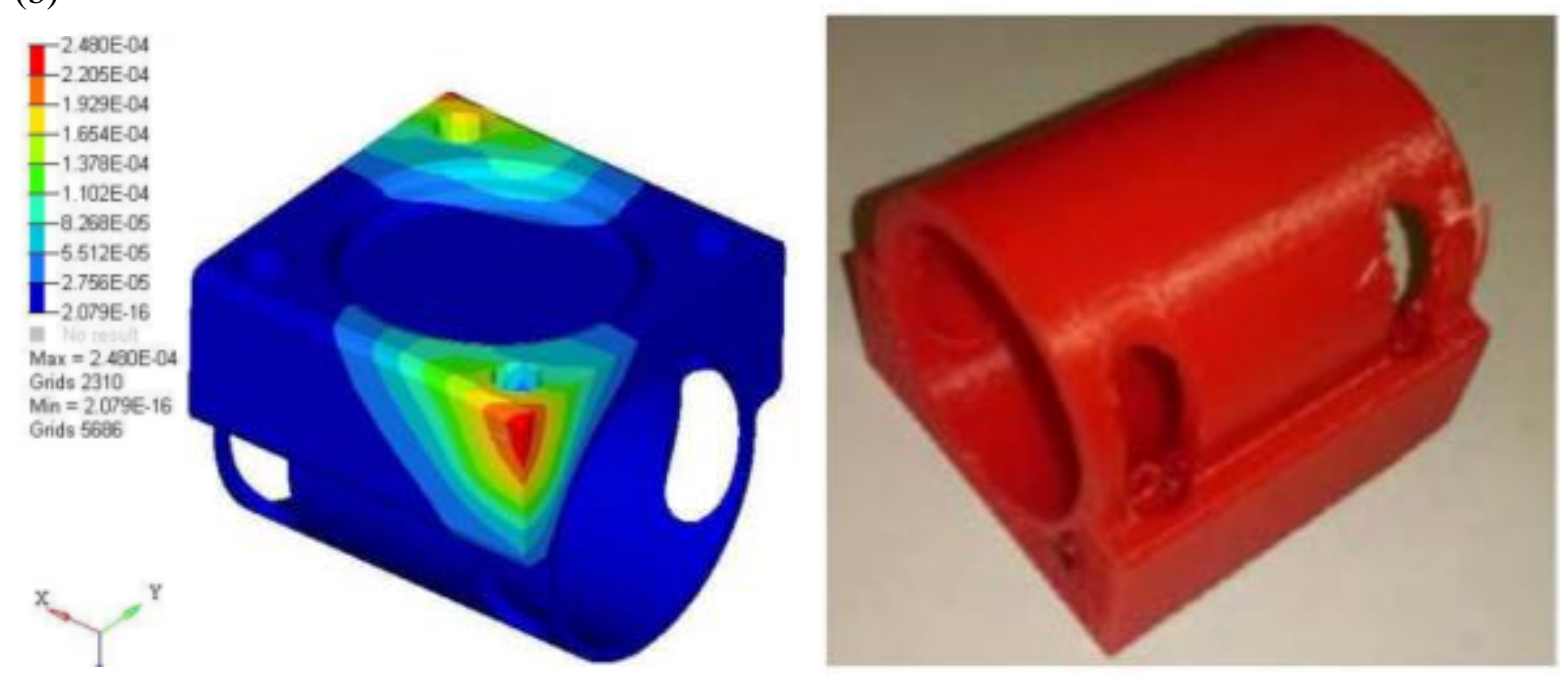

Figure 15.

(b)
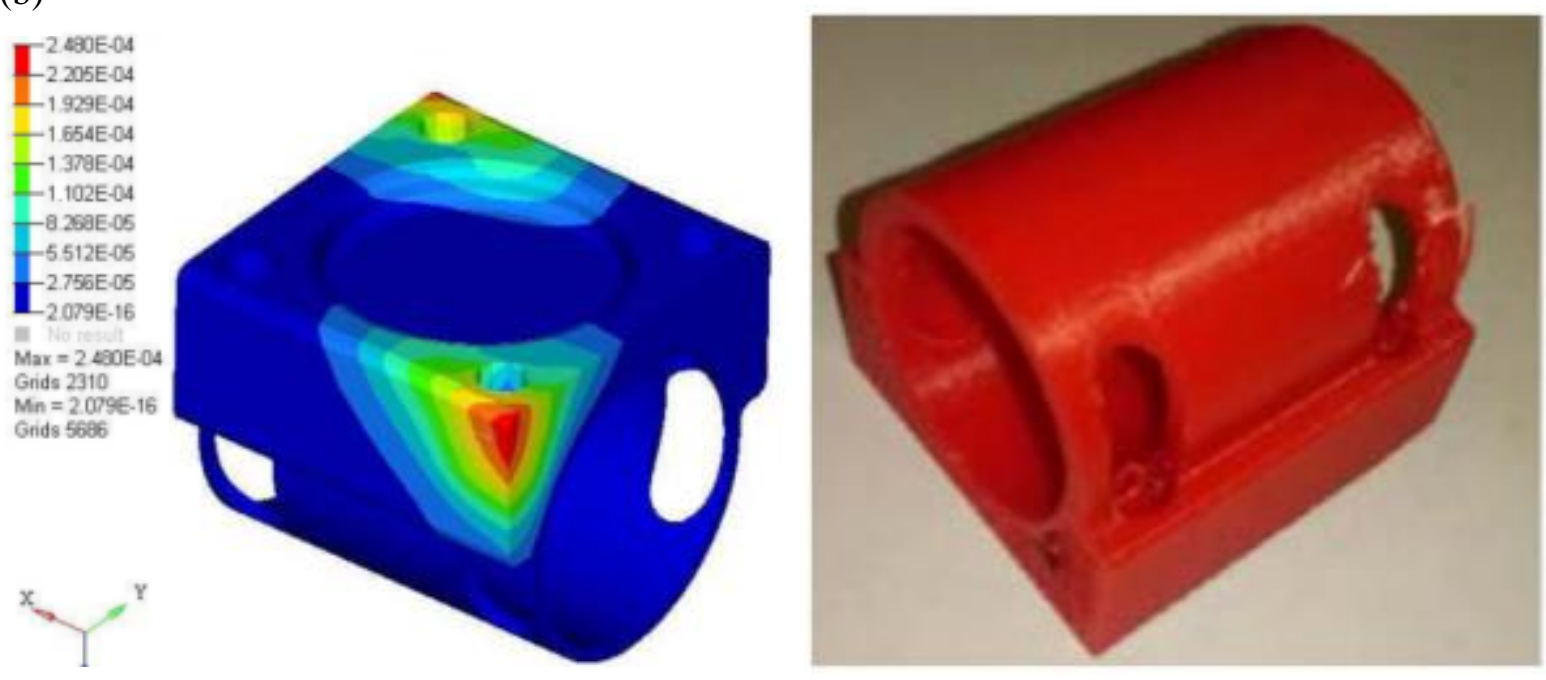

Figure 15: UAV bracket (a) Topology optimisation results, (b) FDM ABS components ${ }^{[118]}$, Free to copy and redistribute.

FDM enables designers to combine parts and consolidate them into one object, which reduces assembling steps. A reduction in the assembly processes has a significant effect on reducing 
manufacturing costs and production issues. By eliminating or reducing assembly operations, there is no need to have dedicated fixtures, jigs, and fasteners. In addition, possible assembly issues in welding or joining are minimized. In addition, in most cases, the performance of consolidated parts is better than assemblies. Furthermore, parts consolidation reduces production, inspection, and management complexity. An Example of parts consolidation is shown in

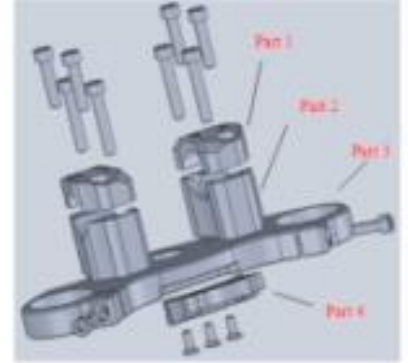

(a) exploded view

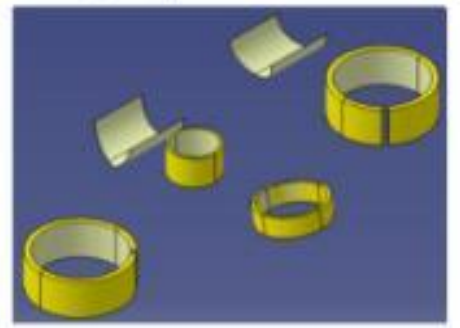

(c) functional surfaces extraction (d) functional volume generation

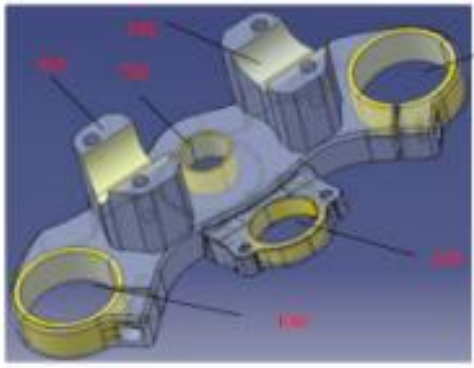

(b) define functional surfaces

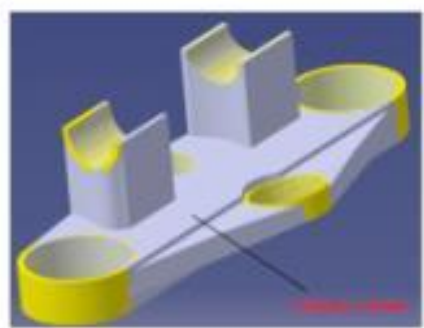

(e) homogeneous lattice structure and skin

Figure 16. The original assembly of stainless triple clamp consists of 19 parts and was redesigned to achieve a single part with part consolidation ${ }^{[119]}$. It can significantly be used to consolidate the number of parts in UAVs offering simple, easy to manufacture, cost effective and high performance UAVs. 


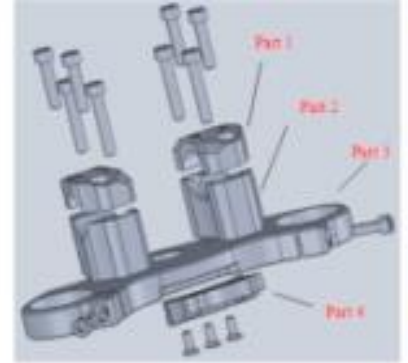

(a) exploded view

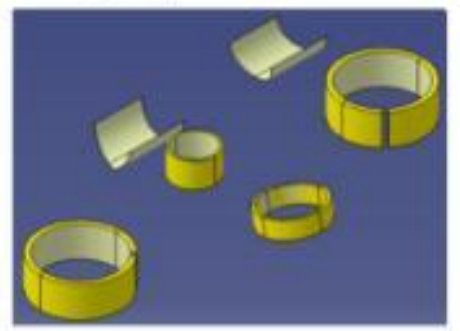

b) define functional surfaces
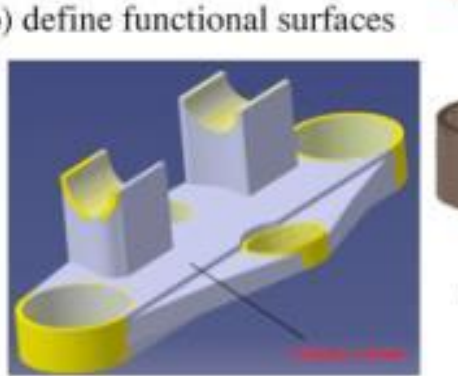

(e) homogeneous lattice structure and skin

(c) functional surfaces extraction (d) functional volume generation

Figure 16: Parts consolidation example of a triple clamp ${ }^{[119]}$, with kind permission from Elsevier.

A new relation between UAVs and FDM was introduced by M. Kovač ${ }^{[120]}$ and R. StuartSmith ${ }^{[121,122]}$. The authors proved that UAVs can be used to carry FDM print heads. The aim of those projects is to have a swarm of robots and UAVs, which build up an architecture by using additive manufacturing techniques. The new term of this research area named as aerial additive building manufacture $(\mathrm{AABM})^{[121]}$. 


\subsection{Challenges}

FDM holds promising potentials and advantages to become one of the most important technologies for future industries, especially for UAVs. However, most of the research work is still in its infancy and there are challenges need to be addressed so that users can take into account the technology issues and how to get the most out of FDM.

FDM can fabricate a limited number of materials, typically thermoplastic polymer, owing the narrow range of processing temperature that can be employed. As such, FDM components have limited properties, which may not satisfy all of the requirements of UAVs. Although that FDM material development introduced new types of materials such as composites, ceramics and metals, most of the new materials are not commercially produced and limited to proof of concept studies. On the other hand, the layer-by-layer nature of FDM produces parts with anisotropic properties. It was found that part orientation, layer thickness, and feed rate have a great effect on the mechanical properties. Therefore, a good choice of part orientation and process parameters is important to overcome or reduce the effect of these problems ${ }^{[123,124]}$. Additionally, parts fabricated by using FDM have induced porosity. Porosity formation is mainly because of the non-ideal deposition, which has a significant effect on the strength of the FDM part. Reducing or eliminating induced porosity is necessary to reduce inconsistency between the printed parts and the designed one ${ }^{[125]}$.

Building orientation of the FDM parts does not only affect the mechanical properties but also affects the surface roughness. Therefore, surface-finishing processes such as sanding, resin infiltration, post processing machining and acetone vapour polishing can be used to improve the surface quality ${ }^{[88-91]}$. The need for support structures is also another limitation of FDM. Although support structures are important to successfully build over-hanged features, they often have negative impacts on quality and productivity of FDM. Support structures cost more time and material for the building process. In addition, removal of the support structures can 
be achieved by using mechanical or chemical post-processing. Users must plan where to place support structures, how to remove them and the impact of removing them on surface quality ${ }^{[87,88]}$. To tackle these issues and qualify the process for the development of UAVs, researches were carried out several studies to improve surface finish, reduce material waste, improve productivity, enhance material properties, and reduce the need for support structures. Statistical design of experiments, genetic optimisation, and multi-objective optimization were extensively employed to optimise building orientation, parts design, and process parameters [126-130]

Another limitation of FDM is the small build platforms in most of the available machines. Therefore, the discussed projects implemented a strategy to break down UAVs into smaller segments in order to accommodate them into small build platforms. Assembly of many printed parts is not only difficult but also affects the total weight of the whole structure, as fasteners are needed to join them. In addition, the assembly process requires more time and effort. BigRep FDM printer is an attempt to increase the build platform with size of over $1 \mathrm{~m}^{3}$ [131].

As AM in general and FDM in particular present great opportunities for designers and manufacturers, they introduced many challenges for inspection and quality control. Since AM simultaneously builds both the part geometry and material, components must be inspected to verify the material defects and geometrical errors. As a result, characterisation and measurements techniques must be improved in order to match the new challenges ${ }^{[132]}$. One clear example is the complex measurement techniques associated with the verification of complex organic geometries that can be created by using AM, as the current standards were not developed for such shapes. In addition, it is challenging to allocate a specific tolerance to organic geometries. Furthermore, the inspection of internal geometries, such as complex cavities, small holes, and channels is more difficult which highlights the importance of 
implementing scanning and non-destructive testing. Thus, inspection and quality control must be integrated with $\mathrm{AM}^{[133,134]}$.

Sustainability and environmental impact of AM are another challenges that need a great depth of understanding ${ }^{[135]}$. Even if the material efficiency of AM parts is high, there is insufficient research regarding the material sustainability ${ }^{[136]}$. Recycling waste of thermoplastic materials into new filaments is a reliable solution to address this challenge. Filament extruders are commercially available and affordable to convert plastic waste to filaments. However, issues such as mixing of colours and degradation in the material lead to a major change in the filaments properties ${ }^{[137,138]}$.

\section{Conclusion}

FDM and UAVs, are fast growing technologies, have attracted a great deal of attention. The availability, flexibility, and cost savings of FDM have gained much interest for fabrication of UAV systems. In addition to research institutions, universities, and industries, successful examples showed that hobbyists significantly contributed in adopting FDM technology for the development of UAVs. Complex structures and embedded electronics of UAVs were built successfully, and showed improvement in the aerodynamics performance and structural efficiency of UAVs. The design freedom of FDM allowed the production of UAV structures, which are difficult to manufacture using conventional techniques and without the use of fixtures or moulds. The discussed examples showed that full understanding of FDM process in the context of UAVs is still insufficient, users must understand the process challenges including building direction, design and processing parameters, small building platforms, slow building rate and the need to use support structures. Additional challenges are related to post processing techniques, materials sustainability, inspection, and quality control. Although most of the process potentials are well known, many of the presented works are still in the early stages and more research are required on the materials, design, control, and 
manufacturing process in order to enhance the process capabilities to fit a broad range of UAVs users.

\section{Biographies}

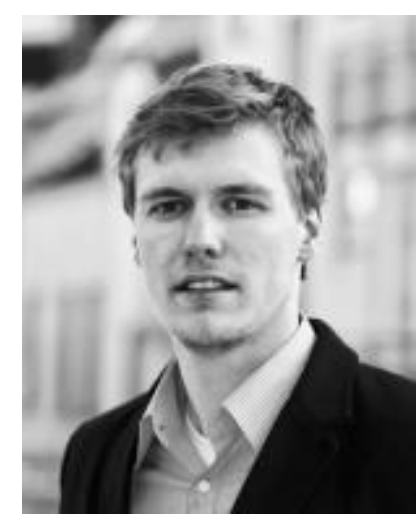

S. Helge Klippstein is a master student in Advanced Product Design Engineering at Kingston University. In a cooperative system with Airbus Operations GmbH Bremen he achieved his craft certificate for aircraft mechanics (2008) and studied in the same time in the bachelor course Mechanical Production and Engineering at the University of Applied Science Bremen (2009). He worked for three years in the Performance and Improvement department of Airbus Bremen before he started his master studies in London.

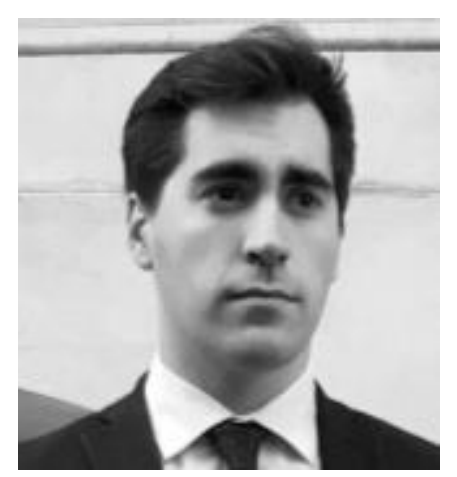

Alejandro Diaz de Cerio is a Research Associate working for the UAV department at Kingston University London after completing his MSc in Mechatronics master studies, focusing on quad-copter's design and control. Previously he completed his Bachelor's degree in Mechanical Engineering at Alfonso X "El Sabio" Madrid, Spain. He has been coauthor in the elaboration of a Journal paper, in review stage for its publication, for the Aerospace 
Science and Technology journal, being the dual-axis tilting quad-copter design, modelling and control the research topic.

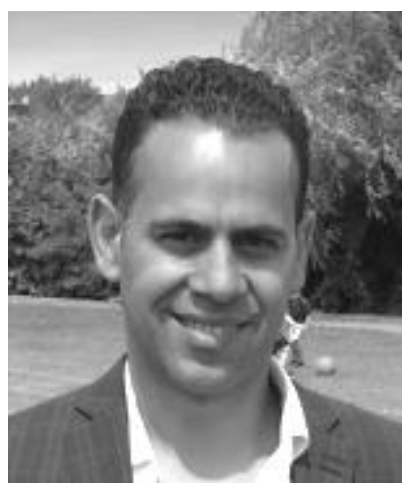

Dr Hany Hassanin is a senior lecturer in engineering design and manufacturing at Kingston University. He received his $\mathrm{PhD}$ in advanced manufacturing and materials using micro/nano technology from the University of Birmingham (2010), MSc degree in mechanical engineering from Helwan University-Egypt, BSc degree in mechanical engineering from Cairo University-Egypt. His research portfolio over the past 10 years has been focused on studying micro/nanotechnology, additive manufacturing (3D printing), mechanical design, computer aided design, metamaterials, precision engineering, finite element analysis, biomedical Engineering, composite materials.

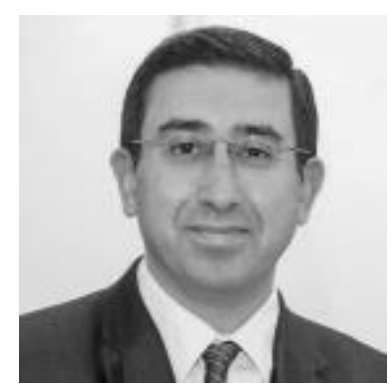

Dr. Yahya Zweiri is the School Director of Research \& Enterprise, Kingston University London, UK, and he is currently visiting associate professor in Robotics Institute, Khalifa University, UAE. He received his PhD from King's College London in 2003. He was involved in defence \& security research projects in the last twenty years at Defence Science and Technology Laboratory (Dstl, Uk), King's College London and King Abdullah II Design and 
Development Bureau (KADDB), Jordan. Dr. Zweiri's central research focus is interaction dynamics between unmanned systems and unknown environments by means of deep learning, machine intelligence, constrained optimization and advanced control. He has published over 80 refereed journal and conference papers; and filed five patents in USA and GB in unmanned systems field.

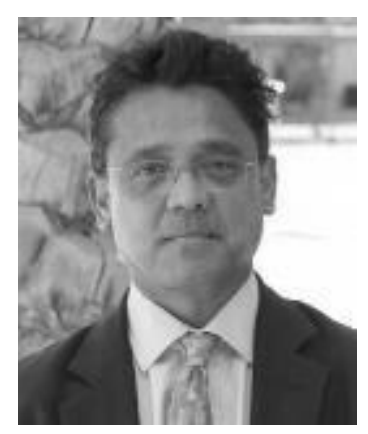

Professor Lakmal Seneviratne is the founding Director of the Robotics Institute, Associate VP for Research and Professor of Mechanical Engineering at Khalifa University, UAE. He is also the Technical Director of the Mohammed Bin Zayed International Robotics Challenge. Prior to joining Khalifa University, he was Professor of Mechatronics, the founding Director of the Centre for Robotics Research and the Head of the Division of Engineering, at King's College London. His main research interests are centred on robotics and automation, with particular emphasis on increasing the autonomy of robotic systems interacting with complex dynamic environments. He has published over 350 peer reviewed publications on these topics. 


\section{References}

[1] A. Sanna and B. Pralio, Simulation and control of mini UAVs, presented at Proceedings of the 5th WSEAS international conference on Simulation, modelling and optimization, Corfu, Greece, 2005.

[2] S. D'Oleire-Oltmanns, I. Marzolff, K. D. Peter, and J. B. Ries, Remote Sensing 2012, 4, 3390-3416.

[3] Q. Feng, J. Liu, and J. Gong, Water 2015, 7, 1437-1455.

[4] Y. B. Huang, S. J. Thomson, W. C. Hoffmann, Y. B. Lan, and B. K. Fritz, International Journal of Agricultural and Biological Engineering 2013, 6, 1-10.

[5] F. Mancini, M. Dubbini, M. Gattelli, F. Stecchi, S. Fabbri, and G. Gabbianelli, Remote Sensing 2013, 5, 6880-6898.

[6] K. G. Nikolakopoulos, K. Soura, I. K. Koukouvelas, and N. G. Argyropoulos, Journal of Archaeological Science: Reports 2016.

[7] G. Romeo and G. Frulla, HELIPLAT®: Design of High altitude Very-long Endurance Solar Powered Platform for Telecommunication and Earth Observation Applications, in European Space Agency, (Special Publication) ESA SP, ed, 2001, 516-527.

[8] B. Custers, The Future of Drone Use: Opportunities and Threats from Ethical and Legal Perspectives: T.M.C. Asser Press, 2016.

[9] A. Harmat, M. Trentini, and I. Sharf, Journal of Intelligent and Robotic Systems: Theory and Applications 2015, 78, 291-317.

[10] B. D. Reineman, L. Lenain, and W. K. Melville, Journal of Atmospheric and Oceanic Technology 2016, 33, 2029-2052.

[11] C. Torresan, A. Berton, F. Carotenuto, S. F. D. Gennaro, B. Gioli, A. Matese, et al., International Journal of Remote Sensing 2017, 38, 2427-2447.

[12] A. İşitirici and E. Altuğ, Journal of Intelligent and Robotic Systems: Theory and Applications 2017, 1-19.

[13] M. F. Bin Abas, A. S. Bin Mohd Rafie, H. Bin Yusoff, and K. A. Bin Ahmad, Chinese Journal of Aeronautics 2016, 29, 1159-1177.

[14] E. Cetinsoy, Design and control of a gas-electric hybrid quad tilt-rotor UAV with morphing wing, presented at 2015 International Conference on Unmanned Aircraft Systems, ICUAS 2015, 2015.

[15] K. Essa, H. Hassanin, M. Attallah, N. Adkins, A. Musker, G. Roberts, et al., Applied Catalysis A: General 2017.

[16] A. Uriondo, M. Esperon-Miguez, and S. Perinpanayagam, Proceedings of the Institution of Mechanical Engineers, Part G: Journal of Aerospace Engineering 2015, 229, 2132-2147.

[17] R. Leal, F. M. Barreiros, L. Alves, F. Romeiro, J. C. Vasco, M. Santos, et al., International Journal of Advanced Manufacturing Technology 2017, 1-7.

[18] P. Bubna, M. P. Humbert, M. Wiseman, and E. Manes, SAE Technical Papers 2016, 0329, 8 .

[19] C. K. Chua and K. F. Leong, 3D Printing and Additive Manufacturing: Principles and Applications: World Scientific, 2014.

[20] L.-C. Zhang and H. Attar, Advanced Engineering Materials 2016, 18, 463-475.

[21] Y. L. Hao, S. J. Li, and R. Yang, Rare Metals 2016, 35, 661-671.

[22] J.-Y. Lee, W. S. Tan, J. An, C. K. Chua, C. Y. Tang, A. G. Fane, et al., Journal of Membrane Science 2016, 499, 480-490.

[23] Y. L. Yap and W. Y. Yeong, Virtual and Physical Prototyping 2014, 9, 195-201.

[24] X. Yan and P. Gu, Computer-Aided Design 1996, 28, 307-318. 
[25] G. N. Levy, R. Schindel, and J. P. Kruth, CIRP Annals - Manufacturing Technology 2003, 52, 589-609.

[26] S. Li, H. Hassanin, M. M. Attallah, N. J. Adkins, and K. Essa, Acta Materialia 2016, $105,75-83$.

[27] C. Qiu, S. Yue, N. J. Adkins, M. Ward, H. Hassanin, P. D. Lee, et al., Materials Science and Engineering: A 2015, 628, 188-197.

[28] J.-P. Kruth, M. C. Leu, and T. Nakagawa, CIRP Annals - Manufacturing Technology 1998, 47, 525-540.

[29] D. Costa. (Oct 24, 2015) Why 3D Printing Matters. PC Magazine Available: http://uk.pcmag.com/feature/72516/pc-magazine-november-issue-now-on-sale-why3d-printing-matte

[30] I. J. Petrick and T. W. Simpson, Research-Technology Management 2013, 56, 12.

[31] Wohlers-Associates-Inc., Metal Powder Report 2016, 71, 288.

[32] J. R. Tumbleston, D. Shirvanyants, N. Ermoshkin, R. Janusziewicz, A. R. Johnson, D. Kelly, et al., Science 2015, 347, 1349-1352.

[33] A. Cazón, P. Morer, and L. Matey, Proceedings of the Institution of Mechanical Engineers, Part B: Journal of Engineering Manufacture 2014, 228, 1664-1675.

[34] S. Nowotny, S. Thieme, S. Scharek, T. Rönnefahrt, and R. A. Gnann, FLEXILAS Laser-Präzisionstechnologie zum Auftragschweißen mit zentrischer Drahtzufuhr, in Die Verbindungs Spezialisten 2008, ed, 2008, 318-322.

[35] S. Kaierle, A. Barroi, C. Noelke, J. Hermsdorf, L. Overmeyer, and H. Haferkamp, Physics Procedia 2012, 39, 336-345.

[36] R. Singh, Rapid Prototyping Journal 2014, 20, 69-76.

[37] AMT/8, Additive manufacturing. General principles. Overview of process categories and feedstock, BS EN ISO 17296, First ed, 2015, 8.

[38] J. Long, H. Gholizadeh, J. Lu, C. Bunt, and A. Seyfoddin, Current Pharmaceutical Design 2017, 23, 433-439.

[39] D. D. Gu, W. Meiners, K. Wissenbach, and R. Poprawe, International Materials Reviews 2012, 57, 133-164.

[40] H. Hassanin, K. Essa, C. Qiu, A. M. Abdelhafeez, N. J. Adkins, and M. M. Attallah, Rapid Prototyping Journal 2017, 23, 720.

[41] A. Sabouri, A. K. Yetisen, R. Sadigzade, H. Hassanin, K. Essa, and H. Butt, Energy \& Fuels 2017, 31, 2524-2529.

[42] H. Hassanin, F. Modica, M. A. El - Sayed, J. Liu, and K. Essa, Advanced Engineering Materials 2016, 18, 1544-1549.

[43] Y. J. Liu, S. J. Li, H. L. Wang, W. T. Hou, Y. L. Hao, R. Yang, et al., Acta Materialia 2016, 113, 56-67.

[44] Y. J. Liu, H. L. Wang, S. J. Li, S. G. Wang, W. J. Wang, W. T. Hou, et al., Acta Materialia 2017, 126, 58-66.

[45] H. Bikas, P. Stavropoulos, and G. Chryssolouris, The International Journal of Advanced Manufacturing Technology 2016, 83, 389-405.

[46] K. Kun, Procedia Engineering 2016, 149, 203-211.

[47] N. Mohan, P. Senthil, S. Vinodh, and N. Jayanth, Virtual and Physical Prototyping 2017, 12, 47-59.

[48] D. L. He, F. G. Han, Z. Wang, and Q. F. Liu, Yaoxue Xuebao 2016, 51, 1659-1665.

[49] S. Singh and R. Singh, Rapid Prototyping Journal 2016, 22, 123-143.

[50] J.-Y. Lee, J. An, and C. K. Chua, Applied Materials Today 2017, 7, 120-133.

[51] Z. Zhou, I. Salaoru, P. Morris, and G. J. Gibbons, Development of a direct feed fused deposition modelling technology for multi-material manufacturing, presented at $19^{\text {th }}$ 
International Conference on Material Forming ESAFORM 2016, Nantes, France, October, 2016.

[52] J. Du, Z. Wei, X. Wang, J. Wang, and Z. Chen, Journal of Materials Processing Technology 2016, 234, 332-341.

[53] W.-c. Lee, C.-c. Wei, and S.-C. Chung, Journal of Materials Processing Technology 2014, 214, 2366-2374.

[54] Stratasys. (2015, 05/13). Production-grade Thermoplactic for fortus 3D production systems. Available:

http://usglobalimages.stratasys.com/Main/Files/Material_Spec_Sheets/MSS_FDM_A BSi.pdf

[55] A. R. Torrado, C. M. Shemelya, J. D. English, Y. Lin, R. B. Wicker, and D. A. Roberson, Additive Manufacturing 2015, 6, 16-29.

[56] All3DP. (2017, 01/06/2017). Best Types of 3D Printer Filament: Guide \& Comparison Charts. Available: https://all3dp.com/1/3d-printer-filament-types-3dprinting-3d-filament/\#nylon

[57] T. Mukherjee and N. Kao, Journal of Polymers and the Environment 2011, 19, $714-$ 725.

[58] P. K. Bajpai, I. Singh, and J. Madaan, Journal of Thermoplastic Composite Materials 2014, 27, 52-81.

[59] Ciceri-de-Mondel-srl-Unipersonale. (2016, 05/13). FILOALFA filament. Available: http://www.filoalfa3d.com

[60] G. A. O. Adam and D. Zimmer, CIRP Journal of Manufacturing Science and Technology 2014, 7, 20-28.

[61] K. C. Chuang, J. E. Grady, R. D. Draper, E. S. E. Shin, C. Patterson, and T. D. Santelle, Additive manufacturing and characterization of ultem polymers and composites, presented at CAMX 2015 - Composites and Advanced Materials Expo, Dallas, USA, 2015.

[62] D. Espalin, K. Arcaute, E. Anchondo, A. Adame, F. Medina, R. Winker, et al., Analysis of bonding methods for FDM-manufactured parts, presented at $21^{\text {st }}$ Annual International Solid Freeform Fabrication Symposium - An Additive Manufacturing Conference, SFF 2010, Austin, USA, 2010.

[63] H. Garg and R. Singh, Transactions of the Indian Institute of Metals 2017, 70, 12411244.

[64] N. Saude, N. M. A. Isa, M. Ibrahim, and M. H. I. Ibrahim, Applied Mechanics and Materials 2014, 607, 747-751.

[65] S. Hwang, E. I. Reyes, K. S. Moon, R. C. Rumpf, and N. S. Kim, Journal of Electronic Materials 2015, 44, 771-777.

[66] K. S. Boparai, R. Singh, and H. Singh, Rapid Prototyping Journal 2016, 22, 217-224.

[67] K. Boparai, R. Singh, and H. Singh, Virtual and Physical Prototyping 2015, 10, 59-66.

[68] S. J. Kalita, S. Bose, H. L. Hosick, and A. Bandyopadhyay, Materials Science and Engineering: $C$ 2003, 23, 611-620.

[69] M. Sabino, Z. Fermín, L. Marielys, J. Moret, D. Rodríguez, R. A. Rezende, et al., IFAC Proceedings Volumes 2013, 46, 356-360.

[70] A. Salem, M. Singh, and M. C. Halbig, 3-D Printing and Characterization of Polymer Composites With Different Reinforcements, in Advanced Processing and Manufacturing Technologies for Nanostructured and Multifunctional Materials II: John Wiley \& Sons, Inc., 2015, 113-122.

[71] M. L. Shofner, K. Lozano, F. J. Rodríguez-Macías, and E. V. Barrera, Journal of Applied Polymer Science 2003, 89, 3081-3090. 
[72] F. Ning, W. Cong, J. Qiu, J. Wei, and S. Wang, Composites Part B: Engineering 2015, 80, 369-378.

[73] H. L. Tekinalp, V. Kunc, G. M. Velez-Garcia, C. E. Duty, L. J. Love, A. K. Naskar, et al., Composites Science and Technology 2014, 105, 144-150.

[74] W. Zhong, F. Li, Z. Zhang, L. Song, and Z. Li, Materials Science and Engineering: A 2001, 301, 125-130.

[75] R. Matsuzaki, M. Ueda, M. Namiki, T.-K. Jeong, H. Asahara, K. Horiguchi, et al., Scientific Reports 2016, 6, 23058 EP -.

[76] N. Travitzky, A. Bonet, B. Dermeik, T. Fey, I. Filbert-Demut, L. Schlier, et al., Advanced Engineering Materials 2014, 16, 729-754.

[77] S. Iyer, J. McIntosh, A. Bandyopadhyay, N. Langrana, A. Safari, S. C. Danforth, et al., International Journal of Applied Ceramic Technology 2008, 5, 127-137.

[78] N. Venkataraman, T. McNulty, S. Rangarajan, M. Vidaic, M. J. Matthewson, N. Langrana, et al., Materials Research Society Symposium - Proceedings 1999, 542, 111-117.

[79] A. M. Abdullah, T. N. A. Tuan Rahim, D. Mohamad, H. M. Akil, and Z. A. Rajion, Materials Letters 2017, 189, 307-309.

[80] S. Rajakumar, L. Vijayaraghavan, M. M. Mayuram, and R. Krishnamurthy, Journal of Manufacturing Technology Research 2009, 1, 305-315.

[81] G. Wu, N. A. Langrana, R. Sadanji, and S. Danforth, Materials \& Design 2002, 23, 97-105.

[82] A. K. Sood, R. K. Ohdar, and S. S. Mahapatra, Journal of Advanced Research 2012, 3, 81-90.

[83] G. Alaimo, S. Marconi, L. Costato, and F. Auricchio, Composites Part B: Engineering 2017, 113, 371-380.

[84] R. Anitha, S. Arunachalam, and P. Radhakrishnan, Journal of Materials Processing Technology 2001, 118, 385-388.

[85] A. Barari, H. A. Kishawy, F. Kaji, and M. A. Elbestawi, The International Journal of Advanced Manufacturing Technology 2017, 89, 1969-1974.

[86] H.-C. Song, N. Ray, D. Sokolov, and S. Lefebvre, Computer-Aided Design 2017, 89, 25.

[87] E. Barnett and C. Gosselin, Additive Manufacturing 2015, 8, 95-104.

[88] S. H. Ahn, C. S. Lee, and W. Jeong, Rapid Prototyping Journal 2004, 10, 218-224.

[89] K. H. Jo, Y. S. Jeong, J. H. Lee, and S. H. Lee, International Journal of Precision Engineering and Manufacturing 2016, 17, 1541-1546.

[90] A. Lalehpour and A. Barari, IFAC-PapersOnLine 2016, 49, 42-48.

[91] J. S. Chohan, R. Singh, and K. S. Boparai, Measurement 2016, 94, 602-613.

[92] S. Kannan and D. Senthilkumaran, International Journal of Engineering and Technology 2014, 6, 1047-1052.

[93] F. Guerrero-Villar, E. Torres-Jimenez, R. Dorado-Vicente, and J. I. JiménezGonzález, Procedia Engineering 2015, 132, 78-85.

[94] F. Rayegani, G. C. Onwubolu, A. Nagy, and H. Singh, 2014, V02AT02A010.

[95] I. S. Rêgo, T. V. C. Marcos, D. R. Pinto, R. G. S. Vilela, V. A. B. Galvão, A. Pivetta, et al., Aerospace Science and Technology 2016, 55, 307-313.

[96] S. Daneshmand, C. Aghanajafi, and H. Shahverdi, Journal of Polymer Engineering 2012, 32, 575.

[97] C. Roberts and G. Nicholson. (2014, 05/13). FDM printed fixed wing AUV. Available: http://www.amrc.co.uk/case-studies/fdm-printed-fixed-wing-uav 
[98] Y. O. Aktas, U. Ozdemir, Y. Dereli, A. F. Tarhan, A. Cetin, A. Vuruskan, et al., Journal of Intelligent and Robotic Systems: Theory and Applications 2016, 84, 639664.

[99] P. Keane, NTU and Stratasys 3D Print Operational Drone with Embedded Electronics using Aerospace-grade Material, Nanyang Technological University, Singapore 2016.

[100] D. Reisinger. (2016) Mini Version of DARPA X-Plane Completes Test Flight. PC magazine. Available: http://uk.pcmag.com/drones-1/76854/news/mini-version-ofdarpa-X-plane-completes-test-flight

[101] D. Dahle. (2017, 05/13). Aurora Flight Sciences Maximizes the Benefits of 3D Printed Composite Tooling. Available: http://blog.stratasys.com/2017/04/18/auroramaximizes-the-benefits-of-3d-printed-composite-tooling/

[102] Aurora. (2017, 23/06). XV-24A Lightning Strike. Available: http://www.aurora.aero/lightningstrike/

[103] M. Stern and E. Cohen, Society of Manufacturing Engineers 2013, TP13PUB47, 16.

[104] C. Banfield, J. Kidd, and J. Jacob, Design and development of a 3D printed UAV, presented at $54^{\text {th }}$ AIAA Aerospace Sciences Meeting, San Diego, USA, 2016.

[105] MyMiniFactory. (2017, Web Page). Drones. Available: https://www.myminifactory.com/category/drones

[106] A. Neather. (2017, Web Page). MK XIII Micro Quad. Available: https://www.myminifactory.com/object/mk-xiii-micro-quad-28907

[107] U. S. Peter. (2017, Web Page). StarWars TieFighter Gen 2. Available: https://www.myminifactory.com/object/starwars-tiefighter-gen-2-38107

[108] B. Pickard. (2016, 05/12). Fiber Fighter - Micro FPV Racing Quadcopter Drone. Available: https://www.myminifactory.com/object/fiber-fighter-micro-fpv-racingquadcopter-drone-23015

[109] J. M. Gardner, G. Sauti, J.-W. Kim, R. J. Cano, R. A. Wincheski, C. J. Stelter, et al., Additive Manufacturing 2016, 12, Part A, 38-44.

[110] K. Olasek and P. Wiklak, Journal of Physics: Conference Series 2014, 530, 012009.

[111] M. S. Mirotznik, Z. Larimore, P. Pa, P. Parsons, and M. Mills, Multi-material additive manufacturing of antennas, presented at International Workshop on Antenna Technology, iWAT Florida, USA, 2016.

[112] A. Safari, Ferroelectrics 2001, 263, 45-54.

[113] N. Grimmelsmann, H. Meissner, and A. Ehrmann, IOP Conference Series: Materials Science and Engineering 2016, 137, 012011.

[114] T. Reiner, N. Carr, R. Měch, O. Št'Ava, C. Dachsbacher, and G. Miller, Computer Graphics Forum 2014, 33, 479-486.

[115] I. Zein, D. W. Hutmacher, K. C. Tan, and S. H. Teoh, Biomaterials 2002, 23, 11691185

[116] V. B. Nidagundi, R. Keshavamurthy, and C. P. S. Prakash, Materials Today: Proceedings 2015, 2, 1691-1699.

[117] L. M. Kelly, A. Keane, A. Sobester, and D. Toal, Topology Optimisation: Increasing the Speed and Reliability of Design, in $15^{\text {th }}$ AIAA/ISSMO Multidisciplinary Analysis and Optimization Conference: American Institute of Aeronautics and Astronautics, 2014.

[118] C. Ferro, R. Grassi, C. Seclì, and P. Maggiore, Procedia CIRP 2016, 41, 1004-1010.

[119] S. Yang, Y. Tang, and Y. F. Zhao, Journal of Manufacturing Processes 2015, 20, 444449. 
[120] G. Hunt, F. Mitzalis, T. Alhinai, P. A. Hooper, and M. Kovac, 3D printing with flying robots, presented at Proceedings - IEEE International Conference on Robotics and Automation, Hong Kong, China, 2014.

[121] M. Kovac, R. Stuart-Smith, S. Leuttenegger, M. Srinivasan, R. Ball, C. Williams, et al. (2016, 01/06/2017). Aerial ABM: Aerial Additive Building Manufacturing 3D

Printed Construction Using a Swarm of Aerial Robots. Available: http://www.aerialabm.com

[122] R. Stuart-Smith, Architectural Design 2016, 86, 54-59.

[123] S. H. Ahn, M. Montero, D. Odell, S. Roundy, and P. K. Wright, Rapid Prototyping Journal 2002, 8, 248-257.

[124] K. Chockalingam, N. Jawahar, and J. Praveen, Materials and Manufacturing Processes 2016, 31, 2001-2010.

[125] K. C. Ang, K. F. Leong, C. K. Chua, and M. Chandrasekaran, Rapid Prototyping Journal 2006, 12, 100-105.

[126] Y. R. Kumar, International Journal of Materials Engineering Innovation 2012, 3, 228-246.

[127] V. Vijayaraghavan, A. Garg, J. S. L. Lam, B. Panda, and S. S. Mahapatra, International Journal of Advanced Manufacturing Technology 2015, 78, 781-793.

[128] P. K. Gurrala and S. P. Regalla, Virtual and Physical Prototyping 2014, 9, 127-138.

[129] G. Arumaikkannu, N. Uma Maheshwaraa, and S. Gowri, A genetic algorithm with design of experiments approach to predict the optimal process parameters for FDM, presented at $16^{\text {th }}$ Solid Freeform Fabrication Symposium, SFF 2005, USA, 2005.

[130] P. M. Pandey, K. Thrimurthulu, and N. V. Reddy, International Journal of Production Research 2004, 42, 4069-4089.

[131] H. BigRep Gmb. (2017, Web Page). BigRep-One: The Most Advanced Large Scale 3D Printing Experience. Available: https://bigrep.com/bigrep-one/\#

[132] T. Huang, S. Wang, and K. He, Quality control for fused deposition modeling based additive manufacturing: Current research and future trends, presented at The $1^{\text {st }}$ International Conference on Reliability Systems Engineering, ICRSE Beijing, China 2015.

[133] S. Fulga, A. Davidescu, and I. Effenberger, Conceptual approach for an in-line quality control system in Additive Manufacturing Powder Bed Fusion processes, presented at International Conference on Computing and Solutions in Manufacturing Engineering Braşov, Romania, 2017.

[134] R. Deffley, B. Farrar, and P. Carroll, Quality control measures critical to the adoption of sustainable additive manufacturing component production, presented at Euro PM 2014 Congress and Exhibition, Salzburg, Austria, 2014.

[135] S. Ford and M. Despeisse, Journal of Cleaner Production 2016, 137, 1573-1587.

[136] M. Despeisse, M. Yang, S. Evans, S. Ford, and T. Minshall, Procedia CIRP 2017, 61, 594-599.

[137] P. Mägi, A. Krumme, and M. Pohlak, Material recycling and improvement issues in additive manufacturing, presented at Proceedings of the International Conference of DAAAM Baltic "Industrial Engineering", Tallinn, Estonia, 2015.

[138] J. Pakkanen, D. Manfredi, P. Minetola, and L. Iuliano, About the Use of Recycled or Biodegradable Filaments for Sustainability of 3D Printing, in Sustainable Design and Manufacturing 2017: Selected papers on Sustainable Design and Manufacturing, Cham: Springer International Publishing, 2017, 776-785.

[139] H. Wu, D. Li, Y. Tang, B. Sun, and D. Xu, Journal of Materials Processing Technology 2009, 209, 5886-5891. 
[140] R. E. Williams, S. N. Komaragiri, V. L. Melton, and R. R. Bishu, Journal of Materials Processing Technology 1996, 61, 173-178.

[141] S. Junk, W. Schröder, and S. Schrock, Procedia CIRP 2017, 60, 241-246.

[142] Rigid.ink. (2016, 05/13). The Open Source Drone Project. Available: https://www.myminifactory.com/object/the-open-source-drone-project-24489

[143] C. Anderson. (2016, Web Page). Design files for IRIS+ now open source. Available: http://diydrones.com/profiles/blogs/design-files-for-iris-now-open-source

[144] MiniQuadClub. (2017, 05/12). The Mini Quad Club Shop 2017. Available: http://shop.miniquadclub.com/product-category/accessories/3d-printables/

[145] C. Wyman. (2017, 05/14). World's First Jet-Powered, 3D Printed UAV Tops 150 MPH with Lightweight Stratasys Materials. Available: http://blog.stratasys.com/2015/11/09/aurora-uav-3d-printing/ 